\title{
A importância da unidade gestora nos regimes próprios de Previdência Social: análise da situação dos estados e do Distrito Federal
}

\author{
Fernando Ferreira Calazans \\ Secretaria de Gestão Previdenciária do Município de Belo Horizonte \\ Marcus Vinicius de Souza \\ Instituto de Previdência dos Servidores do Estado de Minas Gerais \\ Karina Damião Hirano \\ Fundação de Previdência Complementar do Estado de São Paulo (SP-Prevcom) \\ Renata Malpica Caldeira \\ Fundação de Previdência Complementar do Estado de São Paulo (SP-Prevcom) \\ Maria de Lourdes Pinheiro da Silva \\ Secretaria da Fazenda do Estado de Alagoas \\ Pedro Emanuel Teixeira Rocha \\ Superintendência de Previdência do Estado da Bahia \\ Marcelo Abi-Ramia Caetano \\ Instituto de Pesquisa Econômica Aplicada
}

\begin{abstract}
Este artigo analisa as experiências dos estados e Distrito Federal no funcionamento das entidades previdenciárias de seus regimes próprios de previdência social (RPPS). Primeiro, descreveram-se as origens e justificativas da exigência de criação de unidade gestora dos RPPSs. Em seguida, a partir de referencial teórico e normativo, foram sistematizadas as propriedades conceituais de unidade gestora. Mediante aplicação de questionário aos representantes dos RPPSs dos estados e Distrito Federal, verificaram-se quais desses entes possuem órgãos previdenciários que atendem às propriedades conceituais de unidade gestora. Os resultados demonstram que poucos órgãos previdenciários podem ser classificados como unidades gestoras e que a fragmentação das atividades de concessão e pagamento das aposentadorias necessita ser revista para proporcionar maior eficiência, transparência e controle na gestão dos RPPSs.
\end{abstract}

Palavras-chave: previdência; servidor público; unidade gestora.

Artigo recebido em 20 abr. 2012 e aceito em 21 nov. 2012. 
La importancia de los sistemas de gestión de la unidad en la seguridad social propio: análisis de la situación de los estados y el Distrito Federal

Este artículo examina las experiencias de los estados y del Distrito Federal acerca de las entidades que operan los sistemas de pensiones de su propia seguridad social (RPPS). En primer lugar, describe los orígenes y justificaciones de la necesidad de unicidad gerencial de los RPPSs. Luego, a partir del referencial teórico y normativo se sistematizan las propiedades conceptuales de "entidad gestora única". Por medio de un cuestionario aplicada a los representantes de los RPPSs de los estados y Distrito Federal, se averiguó cuales tienen entidades previsionales que atienden a las propiedades conceptuales presentadas en este artículo. Los resultados muestran que pocas entidades previsionales pueden ser consideradas como entidad de gestión unificada y que la fragmentación de las actividades de otorgar y pagar las pensiones debe ser revisada para proporcionar mayor eficiencia, transparencia y control en la gestión de RPPSs.

Palabras clave: seguridad; servidor público; la unidad de gestión.

The importance of unit management schemes in own social security: situation analysis of the states and the Distrito Federal

This article examines the experiences of the states and the Distrito Federal of entities operating pension schemes of their own social security (RPPS). First, describing their origins and justifications of the requirement of creating unit manager of RPPSs. Then, from the theoretical and normative properties were systematized conceptual management unit. Through a questionnaire to representatives of RPPSs states and Distrito Federal, there were those who loved welfare agencies have properties that meet the conceptual management unit. The results show that few welfare agencies can be considered as management units and the fragmentation of activities and grant payment of pensions needs to be revised to provide greater efficiency, transparency and control in the management of RPPSs.

KEY WORDs: welfare; public server; single management entity.

\section{Introdução}

Este artigo foi elaborado a partir de estudo realizado pelos autores junto à Escola de Administração Fazendária (ESAF), no âmbito do Fórum Fiscal dos Estados Brasileiros, edição 2011, promovido pelo Ministério da Fazenda, e que, devido à importância e ineditismo do tema abordado, merece ser divulgado. O que se espera, com sua publicação, é permitir aos gestores dos regimes de Previdência Social dos servidores públicos de todo o país realizarem análise introspectiva e tomarem essas informações como referência para o desenvolvimento de melhorias na gestão de seus regimes previdenciários.

A Previdência Social brasileira, nela incluídos os Regimes Próprios de Previdência Social (RPPS), que amparam os servidores públicos das três esferas de governo do país, e o Re-

gime Geral, que protege os trabalhadores da iniciativa privada e os servidores públicos sem a proteção dos RPPSs, possui mais de 49,6 milhões de contribuintes, correspondentes a 53,5\% da população economicamente ativa ocupada (Brasil, 2011). 
Relativamente aos RPPSs, mais de 8 milhões de pessoas, entre servidores públicos e militares ativos, inativos e pensionistas, encontram-se vinculadas a um dos 2.236 RPPSs existentes no país. Juntos, os RPPSs e o Regime Geral de Previdência Social (RGPS) arcaram, em 2009, com uma despesa previdenciária de $\mathrm{R} \$ 360,3$ bilhões, equivalente a 4,3\% e 7,2\%, respectivamente, do Produto Interno Bruto (PIB) nominal de 2009 (Brasil, 2010a, 2010b e 2009).

Os entes federados, em boa parte das vezes, possuem entidades previdenciárias designadas "instituto de previdência". Todavia, essas entidades realizam apenas parte das atividades que são da competência dos RPPSs, deixando principalmente a gestão (concessão, pagamento e manutenção) ${ }^{1}$ das aposentadorias dos servidores públicos para os respectivos órgãos de pessoal do ente federado. Essa situação causa problemas de transparência e descumprimento de preceitos constitucionais, além de incentivar a fragmentação de atividades da responsabilidade dos RPPSs e dificultar o exercício do controle social sobre essa política.

Decorre daí a importância de se buscar a profissionalização da gestão dos RPPSs por meio da criação da unidade gestora que possibilita a consolidação e padronização de tarefas, ganhos de escala, e por meio da democratização da sua gestão mediante compartilhamento do poder decisório e utilização de mecanismos democráticos de participação e diálogo sociais, que possibilitam a busca por um controle mais eficaz dessa política.

Este artigo possui natureza aplicada, exploratória, bibliográfica e documental e tem por objetivo geral analisar as experiências dos estados e do Distrito Federal (DF) na criação, implantação e funcionamento das entidades previdenciárias dos seus RPPSs. Como objetivos específicos, o trabalho pretende descrever as origens e justificativas da exigência de criação de unidade gestora dos RPPSs; descrever o enquadramento normativo e teórico da matéria; sistematizar as propriedades conceituais apontadas nas normas que tratam do tema; verificar quais desses entes possuem órgãos previdenciários que atendem às propriedades conceituais da unidade gestora sistematizadas neste trabalho e discutir as dificuldades de sua implantação; bem como verificar se há relação entre unidade gestora e participação dos funcionários na gestão dos RPPSs; evolução do tempo de resposta a requerimentos de aposentadoria e pensão; e existência de fundo capitalizado.

O artigo está estruturado da seguinte forma. Após esta introdução, a seção 2 descreve as origens e justificativa da obrigatoriedade de criação de unidade gestora para os RPPSs, apresenta o marco regulatório e teórico que envolve a questão e sistematiza as propriedades conceituais de unidade gestora. A seção 3 discute os resultados do trabalho, no que se refere à experiência dos estados e do Distrito Federal na criação e no funcionamento de suas entidades previdenciárias, e a última seção apresenta as considerações finais do artigo.

\footnotetext{
${ }^{1}$ Considera-se "concessão" o ato de proferir decisão de deferimento/indeferimento do benefício; "pagamento" o ato de efetuar o depósito do valor do benefício em conta bancária; e "manutenção" o ato de reajustar ou rever o valor do benefício e de proceder a alterações no cadastro do beneficiário.
} 
Para tanto, a descrição das origens e a justificativa para a exigência da criação de unidade gestora dos RPPSs foram feitas mediante análise da evolução da legislação e da literatura que tratam da matéria.

O marco regulatório e as propriedades conceituais que circundam o tema da unicidade de gestão dos RPPSs foram tratados mediante análise descritiva da legislação contemporânea e o marco teórico pertinente à participação social na consecução das políticas públicas foi desenvolvido mediante revisão bibliográfica.

O enquadramento normativo atual da matéria foi feito por meio da leitura de normas de natureza constitucional, legal e infralegal. Depois, com esteio no conteúdo dessas normas e na discussão da literatura, foram sistematizadas as propriedades conceituais de unidade gestora de RPPS.

Com base na sistematização das propriedades conceituais da unidade gestora foram elaboradas perguntas do questionário dirigido de forma a analisarem os aspectos normativos e teóricos que tratam do tema com vistas a verificar quais dos entes federados que participaram da pesquisa possuem órgãos previdenciários que atendam às propriedades conceituais de unidade gestora sistematizadas neste artigo. O questionário foi distribuído aos representantes dos estados e Distrito Federal, integrantes do Conselho Nacional dos Dirigentes de RPPSs (Conaprev), sendo respondido por $22(81,5 \%)$ desses 27 entes.

Os resultados demonstram que poucas entidades previdenciárias dos entes federados que participaram da pesquisa podem ser consideradas unidades gestoras de seus RPPSs. Demonstram ainda que a visão pretérita de fragmentação da operacionalização das atividades de concessão, pagamento e manutenção de benefícios previdenciários, especialmente de aposentadoria, necessita ser revista a fim de proporcionar maior eficiência, transparência e controle na gestão dos RPPSs. Os resultados demonstram também que a presença da unidade gestora dos RPPSs conjugada com a utilização de mecanismos democráticos de participação e de diálogo sociais permitem a profissionalização da gestão dos RPPSs, maior transparência e busca por um controle mais eficaz dessa política pública.

\section{Origens da obrigatoriedade da unidade gestora dos RPPSs}

Até o advento da Lei no 9.717, que dispõe sobre regras gerais para o funcionamento dos RPPSs, e da Emenda Constitucional (EC) no 20, que promoveu a primeira onda de reformas previdenciárias, diante da complacência legislativa (Caetano, 2006) dos RPPSs e ausência de lógica financeira e atuarial ${ }^{2}$ aplicadas à gestão dos RPPSs, estes eram tratados como apêndices da política de pessoal dos entes federados.

\footnotetext{
${ }^{2}$ Os benefícios dos RPPSs não guardavam correlação com a contribuição, mas com a remuneração do cargo pelo qual o servidor tinha o direito de receber como ativo. Além disso, até 1998, para fins de aposentadoria, havia previsão de contagem em dobro de férias prêmio, bem como do arredondamento na contagem de tempo de serviço.
} 
Na ausência de critérios que garantissem a viabilidade e sustentabilidade financeira dos RPPSs, as despesas com aposentados e pensionistas dos entes federados passaram a comprometer cada vez mais o gasto com pessoal. Referida situação acarretou consideráveis deficits nos RPPSs das três esferas de governo.

Em 1998 (ano de publicação da EC no 20), enquanto no RGPS o deficit financeiro era de $0,7 \%$ do PIB, nos RPPSs federal, estaduais e municipais, considerados conjuntamente, o deficit era de 3,7\% (Giambiagi, 2007), cenário que levou o legislador constituinte derivado a publicar a $\mathrm{EC}$ nํㅜ 20 .

Com a reforma previdenciária de 1998 o Regime Geral e os RPPSs submeteram-se a novos paradigmas. Relativamente aos RPPSs, objeto deste artigo, foram criadas várias regras, entre elas: necessidade de preservação do equilíbrio financeiro e atuarial, caráter contributivo, pleno acesso dos segurados às informações relativas à gestão do regime e participação de representantes dos servidores nas instâncias de decisão em que seus interesses sejam objeto de deliberação, cobertura exclusiva a servidor titular de cargo efetivo, vedação de convênio ou consórcio para pagamento de benefícios previdenciários, vinculação da receita previdenciária e vedação de contagem de tempo fictício.

Em 2003, dando continuidade ao processo de melhoria da gestão dos RPPSs, iniciado com a primeira onda de reformas previdenciárias (Lei no 9.717/1998 e EC no 20/1998), publicou-se a EC no 41. Mencionada Emenda, ao incluir o § 20 ao art. 40 da Constituição Federal de 1988 (CF/88), adiante transcrito, instituiu a obrigatoriedade de manutenção de unidade gestora para os RPPSs de cada ente federado, ressalvado o disposto no art. 142, § 3으, X, da $\mathrm{CF} / 88,{ }^{3}$ que trata dos militares federais, e o art. 42 , $\S 1^{\circ}$, da $\mathrm{CF} / 88,{ }^{4}$ que determina seja aplicado aos militares estaduais o contido naquele dispositivo:

$\S$ 20. Fica vedada a existência de mais de um regime próprio de previdência social para os servidores titulares de cargos efetivos, e de mais de uma unidade gestora do respectivo regime em cada ente estatal, ressalvado o disposto no art. 142, § 3ำ X.

O motivo de criação dessa regra proibitiva da existência de mais de uma unidade gestora adveio da histórica segregação das atividades desenvolvidas pelos RPPSs, haja vista contemplarem servidores de todos os poderes. Essa segregação é confirmada por Souza (2006), ao registrar que, quando da criação do Instituto de Aposentadoria e Pensões dos Servidores do Estado (Ipase), foi atribuído ao Tesouro Nacional o custeio das aposentadorias existentes, o que passou a ser regra para os servidores públicos do país.

\footnotetext{
3 “Art. 142, § 3으 X (...) a lei disporá sobre o ingresso nas Forças Armadas, os limites de idade, a estabilidade e outras condições de transferência do militar para a inatividade, os direitos, os deveres, a remuneração, as prerrogativas e outras situações especiais dos militares (...)."

4 "Art. $42 \S 1^{\circ}$ Aplicam-se aos militares dos Estados, do Distrito Federal e dos Territórios, além do que vier a ser fixado em lei, as disposições do art. 14, § 8o; do art. 40, § 9; e do art. 142, §§ 2o e 3으 (...)."
} 
Em relação ao caso da União, estados e Distrito Federal, a dificuldade é ainda maior, já que, além dos poderes Executivo e Legislativo, comuns à realidade municipal, há o Poder Judiciário, o Tribunal de Contas, o Ministério Público e a Defensoria Pública, que, em certos estados, como Minas Gerais e Bahia, mantêm de forma autônoma a elaboração da folha de pagamento de pessoal.

Ademais, mesmo no âmbito do Poder Executivo há situações em que as aposentadorias são concedidas por órgãos distintos dos que concedem a pensão (Caetano, 2010). A variedade de órgãos com autonomia para conceder e pagar aposentadorias e pensões, aliada ao grande volume de atribuições dos RPPSs, traz dificuldades para a criação e o funcionamento de sua unidade gestora.

Não por acaso, em 2004 foi ajuizada pela Associação dos Magistrados Brasileiros a Ação Direta de Inconstitucionalidade $\mathrm{n}^{\mathrm{0}}$ 3.297-6, pendente de julgamento, ${ }^{5}$ que questiona a validade jurídica do art. 1 o da EC no 41, que incluiu o $\S 20$ do art. 40 da CF/88 (obrigatoriedade de criação de unidade gestora) ao argumento de que a aludida regra teria violado os princípios da autonomia e independência do Judiciário, insculpidos nos arts. 2o e 60, § 4º III, da CF/88.

\subsection{Unidade gestora dos RPPSs: marco regulatório e propriedades conceituais}

Segundo Schwarzer (2009:273), a criação de unidade gestora "se deve à existência de intensa sobreposição de funções na operacionalização dos regimes próprios por diversas entidades e órgãos da Administração Pública”. Mencionada fragmentação ocasiona elevado custo para os RPPSs. Além da sobreposição de funções, a descentralização administrativa dificulta o acesso às informações, impedindo que as projeções atuariais sejam realizadas com precisão e que as políticas previdenciárias sejam planejadas de maneira uniforme.

Ainda de acordo com esse autor,

não se trata, porém, de reduzir ou interferir na autonomia de cada um dos poderes, no que tange à concessão dos benefícios previdenciários dos agentes públicos a eles vinculados. Trata-se apenas de, excetuada a devida concessão para respeitar a autonomia dos Poderes, centralizar os procedimentos com vistas a racionalizar os custos envolvidos na manutenção destes benefícios, bem como ter acesso amplo às informações necessárias ao bom planejamento previdenciário e garantir mais qualidade aos cadastros que servem de base para as avaliações atuariais. (Schwarzer, 2009: 273-274)

Nessa direção, Caetano (2010:11) afirma que a instituição da unidade gestora "amplia os ganhos obtidos por meio das economias de escala e sinergias em decorrência do fim da

\footnotetext{
${ }^{5}$ Disponível em: <www.stf.jus.br/portal/processo/verProcessoAndamento.asp?incidente=2241299>. Acesso em: 4 fev. 2013.
} 
execução das mesmas tarefas por diferentes equipes. Ademais, a fragmentação torna o RPPS mais suscetível a fraudes”. Todavia, ante a quase inexistência de trabalhos dessa natureza, a revisão bibliográfica será tratada mediante análise das normas que versam sobre a matéria. Aludido marco regulatório detém natureza constitucional, legal e infralegal.

Quanto ao aspecto constitucional (art. 40, § 20 da CF/88), "fica vedada a existência de mais de um RPPS para os servidores titulares de cargos efetivos, e de mais de uma unidade gestora do respectivo regime em cada ente", cuja semântica ("unidade gestora") já irradia a ideia de unicidade. Vale ressalvar que aos militares, que possuem regime previdenciário diferenciado dos servidores, é autorizada a possibilidade de unidade gestora apartada.

Relativamente ao aspecto legal, mesmo que previsto apenas no âmbito federal, o art. 9o, I, da Lei no 10.887/2004 preceitua que "a unidade gestora do regime próprio de previdência dos servidores, prevista no art. 40, § 20, da Constituição Federal: I — contará com colegiado, com participação paritária de representantes e de servidores dos Poderes da União, cabendolhes acompanhar e fiscalizar sua administração".

Por sua vez, o inciso I do art. 15 da Orientação Normativa no 02/2909, elaborada pelo Ministério da Previdência Social (MPS), estabelece que os RPPSs sejam administrados por unidade gestora vinculada ao Poder Executivo que "contará com colegiado ou instância de decisão, no qual será garantida a representação dos segurados, cabendo-lhes acompanhar e fiscalizar sua administração", quedando-se silente no que pertine à garantia da representação paritária (mesma quantidade de representantes dos servidores públicos e do governo).

Todavia, a garantia de representação dos trabalhadores em órgãos públicos em que seus interesses previdenciários sejam objeto de discussão e deliberação prevista no art. 10 da $\mathrm{CF} / 88$, regra criada no período pós-ditatorial, somente foi instituída com vistas a garantir que os trabalhadores deliberassem sobre seus direitos previdenciários, o que seria impossível se não houvesse a paridade de representantes dos beneficiários e do governo.

Isso porque, na ausência de paridade, nas situações em que houver divergência de entendimento entre os representantes dos beneficiários, in casu, os dos servidores públicos e os do governo, as pretensões do funcionalismo são enfraquecidas diante das diretrizes de governo, fazendo com que o processo decisório mantenha-se desequilibrado (Calazans, 2010). ${ }^{6}$

Nesse sentido, não há razão para garantir representação, que não seja paritária, de trabalhadores em espaços públicos onde não tenham poder de veto sobre as pretensões governamentais (ou seja, onde não haja partilha efetiva de poder entre eles e administração pública) que atentem contra seus interesses previdenciários.

Segundo o inciso V do art. 2º da aludida Orientação, considera-se "unidade gestora"

a entidade ou órgão integrante da estrutura da administração pública de cada ente federativo que tenha por finalidade a administração, o gerenciamento e a operacionalização do RPPS, in-

\footnotetext{
${ }^{6}$ Para aprofundamento do estudo sobre representação e participação social em conselhos gestores de RPPSs, confira Calazans (2010).
} 
cluindo a arrecadação e gestão de recursos e fundos previdenciários, a concessão, o pagamento e a manutenção dos benefícios.

A administração de um RPPS envolve diversas atividades além das atinentes à gestão propriamente dita, quais sejam: arrecadação e gestão de recursos, além da concessão, pagamento e manutenção de, no mínimo, aposentadorias e pensões. No mínimo, porque a CF/88, em seu art. 40, previu apenas aposentadoria e pensão como benefícios previdenciários dos RPPSs e também porque o $\S 3^{\circ}$ do art. 10 do Decreto $n^{\circ}$ 3.048/1999 preceitua que "entendese por regime próprio de previdência social o que assegura pelo menos as aposentadorias e pensão por morte previstas no art. 40 da Constituição Federal".

Primeiramente, cite-se a atividade de arrecadação das contribuições a cargo do segurado e da entidade patronal destinadas ao custeio dos RPPSs. A previsão de criação dessas contribuições sociais está contida no art. 149, caput e § 1丷o, ambos da CF/88.

Outra maneira de captação de recursos refere-se à realização da compensação financeira com o RGPS, descrita no § 9o do art. 201 da CF/88, dotado de eficácia pela Lei oํ 9.796/1999, regulamentada pelo Decreto nํ 3.112/1999.

Com a arrecadação dos recursos, faz-se necessário geri-los de forma eficiente e capaz de garantir o equilíbrio financeiro e atuarial do sistema, princípio insculpido no art. 40, caput, da CF/88. A aplicação desses recursos está contida no inciso IV do art. 6o da Lei no 9.717/1998, regulamentada pela Resolução no 3.922/2010, do Conselho Monetário Nacional, que dispõe sobre as aplicações dos recursos dos RPPSs.

A arrecadação e a aplicação dos recursos são feitas com o fim precípuo e mediato de realizar as tarefas de concessão, pagamento e manutenção de benefícios previdenciários de aposentadoria e pensão por morte, cujas regras estão previstas no art. 40 da CF/88.

Para que certo órgão seja considerado unidade gestora, o art. 16 da citada Orientação Normativa $\mathrm{n}^{\circ} 02$ prevê que a unidade deverá gerenciar direta ou indiretamente a concessão, o pagamento e a manutenção, no mínimo, das aposentadorias e pensões concedidas a partir da vigência da EC no 41 de todos os poderes do ente federado. O gerenciamento direto se dá quando a execução é feita pela unidade gestora do RPPS e o indireto, quando a execução é descentralizada, mas a unidade gestora tem o controle sobre seu desenvolvimento, como quando todos os benefícios são concedidos por um sistema cujas regras de negócio foram desenvolvidas pela unidade gestora.

Segundo aludida regra, dimanada do MPS, a unidade gestora deve ser exigida para as aposentadorias e pensões (únicos benefícios previdenciários previstos para os RPPSs pela CF/88) concedidas a partir da Emenda no 41 , já que a obrigatoriedade de exigência da unidade gestora para os RPPSs se deu com a publicação dessa emenda.

Por sua vez, a Portaria MPS no 204/2008, por seu art. 5o, V, ao descrever os critérios exigidos para emissão do Certificado de Regularidade Previdenciária (CRP), lista a existência de colegiado ou instância de decisão em que seja garantida a representação dos segurados do RPPS. 
Igualmente, a Portaria MPS no 402/2008, em seu art. 10, estabelece o seguinte:

Art. 10 (...)

$\S 1^{\circ}$ Entende-se por unidade gestora a entidade ou órgão integrante da estrutura da Administração Pública de cada ente federativo, que tenha por finalidade a administração, o gerenciamento e a operacionalização do RPPS, incluindo a arrecadação e gestão de recursos e fundos previdenciários, a concessão, o pagamento e a manutenção dos benefícios.

$\S 2$ - A entidade gestora única deverá gerenciar, direta ou indiretamente, a concessão, o pagamento e a manutenção, no mínimo, dos benefícios de aposentadoria e pensão concedidos a partir da publicação da Emenda Constitucional no 41, de 2003, de todos os poderes, órgãos e entidades do ente federativo.

$\S 3$ 을 entidade gestora única contará com colegiado ou instância de decisão, no qual será garantida a representação dos segurados.

Mesmo antes da exigência da unidade gestora dos RPPSs, advinda com a publicação da EC no 41/2003, a própria CF/88 e a Lei 9.717/1998 já garantiam a participação dos servidores nos colegiados e instâncias de decisão em que seus interesses sejam objeto de deliberação.

A CF/88, em seu art. 10, prevê que "é assegurada a participação dos trabalhadores e empregadores nos colegiados dos órgãos públicos em que seus interesses profissionais ou previdenciários sejam objeto de discussão e deliberação".

Por sua vez, a Lei no 9.717/1998, em seu art. 1ํㅡ, VI, prevê que fica garantido o pleno acesso dos segurados às informações relativas à administração do regime e participação de representantes dos servidores ativos e inativos nos colegiados e instâncias de decisão em que seus interesses sejam objeto de discussão e deliberação.

A previsão do funcionamento de conselhos de administração e fiscal no âmbito dos RPPSs e da própria existência das unidades gestoras já existe desde a vigência da citada Lei nº 9.717/1998. Mencionada afirmativa pode ser extraída do conteúdo do seu art. 8o, segundo o qual os membros dos conselhos administrativo e fiscal poderão ser responsabilizados por atos contrários à Lei no 9.717 . Veja-se:

Art. 8o - Os dirigentes do órgão ou da entidade gestora do regime próprio de previdência social dos entes estatais, bem como os membros dos conselhos administrativo e fiscal dos fundos de que trata o art. 6을 respondem diretamente por infração ao disposto nesta Lei, sujeitando-se, no que couber, ao regime repressivo da Lei no 6.435 , de 15 de julho de 1977, e alterações subsequentes, conforme diretrizes gerais.

A necessidade de manutenção de dois conselhos, um para gerir o RPPS e outro para fiscalizá-lo, é notória, já que não cabe ao órgão responsável pela administração do regime a responsabilidade por fiscalizar os seus próprios atos de gestão. 


\subsection{Gestão compartilhada de RPPSs: origens, virtudes e desafios da participação social}

Além da criação da unidade gestora para os RPPSs, o compartilhamento da sua gestão é uma das formas para se buscar transparência e controle social mais eficaz dessa política.

Sob o enfoque democrático participativo, os conselhos gestores foram nacionalmente institucionalizados nos anos 1990, num cenário em que se buscava a democratização, no período pós-ditadura militar, e a descentralização, levada a efeito com a reforma do aparelho de Estado. Em paralelo a essa conjuntura de quase nula participação social, havia (e atualmente há) ambiente político desfavorável, repleto de níveis de desigualdade e exclusão social. ${ }^{7}$

A participação de representantes da sociedade civil nos conselhos gestores nasceu da crítica ao comportamento autorreferido da burocracia estatal e da intenção de se estabelecer maneiras de controlar diretamente a prestação dos serviços públicos (Clad, 2000). Nesse sentido, Silva, Jaccoud e Beghin (2005) salientam que a construção (ou reconstrução) dos conselhos, na década de 1990, baseou-se nas críticas ao padrão de relação existente entre Estado e sociedade, marcado pela inexistência de processo decisório democratizado e ineficiência do aparelho estatal.

A crise fiscal, as transformações operadas pela reestruturação do capitalismo - entre elas, a globalização e a terceira revolução industrial —, somadas às atividades executadas ineficiente, monopólica e exclusivamente pelo Estado, o agravamento dos problemas sociais e a insatisfação dos cidadãos com a qualidade dos serviços públicos criaram condições que levaram diversos países à realização de reformas estruturais distintas (Clad, 2000).

Vários países enxugaram o aparelho de Estado com vistas a reduzir o gasto público, descentralizaram a execução das políticas e flexibilizaram a administração mediante a criação de variados regimes de trabalho. Houve outros que, além disso, modificaram a forma de executar as políticas públicas, inserindo representantes da sociedade em seu processo decisório (Clad, 2000; Tatagiba, 2002; Silva, Jaccoud e Beghin, 2005).

Silva, Jaccoud e Beghin (2005) asseveram que, durante a década de 1990, ganhou força uma leitura segundo a qual o Estado detinha baixa capacidade de implementação de políticas, que, aliada à crise econômica, estimulou o governo a buscar parcerias privadas.

Diante desse cenário a administração pública foi obrigada a criar mecanismos para uma gestão mais efetiva em termos de resultados de execução das políticas e mais responsiva em relação aos cidadãos. Em razão disso, o Centro Latinoamericano de Administración para el Desarrollo (2000) apontou cinco ferramentas, complementares entre si, para prover as formas de responsabilização do Estado: os controles procedimentais clássicos (eleições, Controlado-

\footnotetext{
${ }^{7}$ Há consenso de que a pobreza atual é alta para um país com o nível de renda per capita do Brasil, o que se explica por alta desigualdade (Textos para Discussão (TDs) no 553 e no 720). Atualmente, vem sendo dispensada atenção às políticas de transferência de renda (TDs nº 929 e no 984), malgrado serem mal focalizadas e beneficiarem mais aos idosos que às crianças (TD no 985) (Brasil, 2004).
} 
ria, Poder Judiciário e Tribunais de Contas), o controle parlamentar e aquele segundo a lógica de resultados, além da concorrência supervisionada (Estado como coordenador da ação coletiva) e da participação social (accountability vertical).

Essa última maneira, objeto de análise desta subseção, é requisito fundamental para o amadurecimento da governabilidade na medida em que se trata de instrumento capaz de aproximar o aparelho de Estado da sociedade e de remodelar e ampliar o espaço público.

Sucede que a administração pública voltada para o cidadão depende de informação e da institucionalização de formas de participação para os usuários diretos e para os que, direta ou indiretamente, possam de alguma forma ser afetados pelo êxito ou não das políticas.

Um dos problemas de transposição indiscriminada do modelo de reforma do Estado adotado por alguns países desenvolvidos para países latinos foi o da redução da máquina e do deficit fiscal sem, contudo, levar em consideração seus efeitos sobre a prestação dos serviços públicos. Em razão disso, tais serviços se tornaram ainda mais ineficientes e insatisfatórios aos olhos dos cidadãos (Clad, 2000).

Foi diante desse contexto que se buscou uma gestão pública baseada em mecanismos que privilegiem a ampliação do espaço societal. Tais formas de accountability possuem visão voltada para a construção de redes de cooperação e canais de participação dos cidadãos e para a transparência das informações, onde o Estado se torna (ou deveria se tornar) mais permeável às demandas da sociedade.

As mudanças ocorridas, listadas anteriormente (redução do aparelho de Estado para reduzir gasto público, descentralização da execução de políticas e inserção dos cidadãos no processo decisório das políticas), ora sustentaram-se na concepção do projeto democrático participativo, ora, no projeto neoliberal.

Segundo Dagnino (2004), há "confluência perversa" entre tais projetos. "Confluência" porque ambos requerem uma sociedade propositiva na consecução das políticas. E "perversa" porque, apesar de ambos defenderem a participação da sociedade na gestão pública, o projeto participativo objetiva alargar a democracia e o projeto neoliberal, reduzir a máquina pública, que se isenta, cada vez mais, do dever de proporcionar direitos, transferindo a execução das políticas para a sociedade.

Malgrado os dois projetos defenderem a descentralização, no liberal verifica-se um cenário de desregulamentação, em que há o retraimento e a reorientação do papel do Estado; e no democrático são valorizados aspectos de cidadania e democracia participativa, em que se busca a politização da gestão urbana.

Verifica-se assim, com a criação dos conselhos gestores, um alargamento do conceito de esfera pública. Nessa visão, a cidadania não se restringe (ou não deveria se restringir) ao aparelho de Estado, mas também às ações de todos os grupos da sociedade, cujos interesses encontram-se envolvidos naquele debate. Há uma nova concepção de cidadania, que, segundo Silva, Jaccoud e Beghin (2005), refere-se a um controle público não estatal sobre o Estado.

No que se refere aos desafios no funcionamento dos conselhos de políticas públicas, a literatura reconhece que a participação da sociedade no controle e deliberação das políticas é indispensável para produzir accountability real e que ela provocaria um tensionamento nas 
agências, tornando-as mais transparentes e suscetíveis ao controle da sociedade (Tatagiba, 2002). Todavia, "existem divergências de concepções sobre suas virtualidades e dificuldades e, em especial, sobre sua capacidade de somar-se ao Estado em busca de uma maior justiça social" (Silva, Jaccoud e Beghin, 2005:379).

Não obstante as inúmeras vantagens que a participação social traz para a consecução e a deliberação das políticas, há desafios para a efetivação dessa nova forma de gerir a coisa pública (Pires, 2011). O primeiro consiste em incorporar boa parte da população na arena de debates, como forma de eliminar a "privatização da sociabilidade", expressão cunhada por Lechner (apud Clad, 2000), sinônimo de confinamento pessoal na vida privada. O segundo busca identificar como fatores sociológicos afetam o grau de participação social, segundo o conceito de capital social elaborado por Putnam (1996), e o terceiro refere-se à intensidade em que as desigualdades sociais impactam a capacidade de participação dos cidadãos.

Putnam (1996) utiliza o conceito de capital social para explicar o desenvolvimento de regiões na Itália e afirma que esse capital diz respeito a certas características da organização social: confiança mútua, normas, sistemas horizontais de participação cívica e cadeias de relações sociais. Mas um bom capital social é composto, principalmente, pela confiança, que favorece a solidariedade e a cooperação espontânea. A confiança transmite certeza quanto aos contratos e leis, podendo gerar previsibilidade e maior cooperação. Segundo o autor, as formas de capital social multiplicam-se com o uso. Mas o raciocínio inverso também é aplicado, pois a inexistência dessas características gera um círculo vicioso: desconfiança, deserção, instituições ruins, exploração, transgressão, corrupção, clientelismo, autoritarismo e ineficiência. Ou seja, o capital social, corporificado em sistemas horizontais de participação cívica, favorece o desempenho do governo e dos arranjos deliberativos, desde que aquele tenha propensão a legitimar esses espaços como verdadeiros ambientes públicos.

\subsection{Sistematização das propriedades conceituais de "unidade gestora de RPPS"}

Ante o conjunto de informações até agora exploradas na seção 2, podem-se sistematizar as propriedades conceituais de unidade gestora de RPPS, de forma que atenda aos seguintes requisitos:

— entidade/órgão integrante da estrutura do ente federado;

— existência individualizada, única, em todos os RPPSs, com exceção dos militares;

- responsabilidade pela administração do RPPS;

- consolidação da execução das atribuições do RPPS;

— atribuições de responsabilidade do RPPS, além da sua administração: arrecadação e gestão de recursos, inclusive os oriundos da compensação financeira como RGPS; concessão, pagamento e manutenção de benefícios;

- gerenciamento direto ou indireto da concessão, pagamento e manutenção de, no mínimo, as aposentadorias e pensões por morte concedidas a partir da EC n 41 de todos os poderes e entidades do ente federado; 
— existência de conselhos de administração e fiscal;

- garantia de representação paritária dos servidores nos conselhos administrativo e fiscal com a finalidade de acompanhar e fiscalizar a gestão do RPPS.

Feita a supracitada sistematização das propriedades de unidade gestora de RPPS, podese conceituá-la como a entidade/órgão integrante da estrutura do ente federado, com existência individualizada, com exceção dos militares, cuja competência é administrar o RPPS, mediante realização consolidada das atividades de arrecadação e gestão de recursos, inclusive os derivados da compensação financeira com o RGPS; concessão, pagamento e manutenção de, no mínimo, aposentadorias e pensões por morte concedidas a partir da vigência da EC nº 41; e que mantenha conselhos de administração e fiscal que garantam a representação paritária dos servidores públicos.

\section{Análise da experiência das entidades gestoras dos RPPSs dos estados e Distrito Federal}

Entre os 26 estados e o Distrito Federal, 22 desses entes federados responderam ao questionário $(81,5 \%)$. Segundo o apêndice A, que lista quais atividades de aposentadoria (concessão, pagamento e manutenção) dos servidores públicos de todos os poderes são desenvolvidas diretamente pelas unidades gestoras dos RPPSs, percebe-se predominância da realização das atividades de pagamento em face das demais.

Aludida predominância explicita a natureza histórica do benefício de aposentadoria dos servidores públicos, que sempre foi tratado como mero apêndice da política de pessoal dos entes federados. No passado, as contribuições dos RPPSs eram cobradas apenas para o custeio da pensão, ficando a cargo do Estado o ônus do pagamento das aposentadorias, encargo cuja origem deriva-se da existência da relação "pro labore facto" havida entre os funcionários e a administração pública.

Nessa condição, o direito à aposentadoria não era condicionado ao (pleno) caráter contributivo, mas à vinculação do funcionário ao ente federado, em que a aposentadoria era considerada uma benesse a ele concedida em virtude dos serviços públicos prestados. Com efeito, a aposentadoria do servidor era tratada como um benefício de natureza estatutária. Sua concessão se resumia basicamente à verificação pela unidade de recursos humanos de vinculação do servidor, detentora de seus registros funcionais, do cumprimento do requisito tempo de serviço e o processamento do pagamento do vencimento do cargo de que era titular somado às parcelas remuneratórias incorporadas ao longo de sua vida funcional. Isso explica, em certa medida, a baixa centralização da execução das atividades pelos institutos de previdência dos RPPSs dos estados e Distrito Federal.

Na ausência de contribuição definida para o custeio da aposentadoria do servidor, a alíquota média dos RPPSs (5\% a 6\%: destinada apenas a arcar com os custos das pensões) era menor do que a fixada para os segurados do RGPS ( $8 \%$ a 11\%) (Brasil, 2002). 
Referida situação denota a realidade da década passada da administração pública, impulsionada pela Reforma de Estado, no sentido de tentar controlar os gastos com pessoal por meio da "folha de pagamento" (Abrucio e Gaetani, 2006). E a preocupação com a aposentadoria é ainda maior, já que os gastos anuais com esse benefício (R \$ 176,2 bilhões) no Brasil suplantam os gastos com pensão (R\$ 73,5 bilhões) em quase 240\% (Brasil, 2010a e 2009).

No que se refere à execução de todas as atividades de aposentadoria (concessão, pagamento e manutenção) pelos entes federados que responderam ao questionário, quando se analisam conjuntamente todos os poderes, nota-se que apenas quatro estados possuem unidades gestoras que executam diretamente todas as atividades de aposentadoria para os servidores de todos os poderes: Tocantins, Sergipe, Minas Gerais e Espírito Santo (quadro 1). Esse resultado demonstra a existência de estrutura fragmentada de realização das atividades que envolvem o benefício de aposentadoria, o que impede o pleno aproveitamento das economias de escala e escopo, além de criar situações de duplicação desnecessária de atividades entre distintos órgãos públicos.

Quadro 1

Unidades gestoras dos RPPSs estaduais e do $\mathrm{DF}^{8}$ que realizam diretamente as atividades de concessão, pagamento e manutenção de aposentadoria dos servidores de todos os poderes e entidades - Brasil - 2011

\begin{tabular}{|l|c|c|c|c|c|c|c|c|c|c|c|c|c|c|}
\hline & RO & AC & AM & RR & PA & AP & TO & MA & PI & CE & RN & PB & PE & AL \\
\hline Executivo administração direta & $\mathrm{x}$ & $\mathrm{x}$ & $\mathrm{x}$ & - & - & $\mathrm{x}$ & $\mathrm{x}$ & - & $\mathrm{x}$ & & & $\mathrm{x}$ & $\mathrm{x}$ & $\mathrm{x}$ \\
\hline Executivo administração indireta & & $\mathrm{x}$ & $\mathrm{x}$ & - & - & & $\mathrm{x}$ & - & $\mathrm{x}$ & & & $\mathrm{x}$ & $\mathrm{x}$ & $\mathrm{x}$ \\
\hline Judiciário & $\mathrm{x}$ & & & - & - & $\mathrm{x}$ & $\mathrm{x}$ & - & & & & & & \\
\hline Legislativo & $\mathrm{x}$ & & & - & - & $\mathrm{x}$ & $\mathrm{x}$ & - & & & & & & \\
\hline Todos os Poderes e Entidades & & & & & & & $\mathrm{x}$ & & & & & & & \\
\hline
\end{tabular}

\begin{tabular}{|l|c|c|c|c|c|c|c|c|c|c|c|c|c|}
\hline & $\mathrm{SE}$ & $\mathrm{BA}$ & $\mathrm{MG}$ & $\mathrm{ES}$ & $\mathrm{RJ}$ & $\mathrm{SP}$ & $\mathrm{PR}$ & $\mathrm{SC}$ & $\mathrm{RS}$ & $\mathrm{MS}$ & $\mathrm{MT}$ & $\mathrm{GO}$ & $\mathrm{DF}$ \\
\hline Executivo administração direta & $\mathrm{x}$ & $\mathrm{x}$ & $\mathrm{x}$ & $\mathrm{x}$ & & $\mathrm{x}$ & $\mathrm{x}$ & $\mathrm{x}$ & - & & - & - & - \\
\hline Executivo administração indireta & $\mathrm{x}$ & $\mathrm{x}$ & $\mathrm{x}$ & $\mathrm{x}$ & & & $\mathrm{x}$ & $\mathrm{x}$ & - & & - & - & - \\
\hline Judiciário & $\mathrm{x}$ & & $\mathrm{x}$ & $\mathrm{x}$ & & & $\mathrm{x}$ & & - & & - & - & - \\
\hline Legislativo & $\mathrm{x}$ & & $\mathrm{x}$ & $\mathrm{x}$ & & & & & - & & - & - & - \\
\hline Todos os Poderes e Entidades & $\mathrm{x}$ & & $\mathrm{x}$ & $\mathrm{x}$ & & & & & & & & & \\
\hline
\end{tabular}

Fonte: Elaborado pelos autores.

Nota: Questionários respondidos.

Observação: Entes que não responderam à pergunta: RR, PA, MA, RS, MT, GO e DF. Ceará não possui unidade gestora para executar as atividades dos RPPSs.

\footnotetext{
${ }^{8}$ Rondônia (RO), Acre (AC), Amazonas (AM), Roraima (RR), Pará (PA), Amapá (AP), Tocantins (TO), Maranhão (MA), Piauí (PI), Ceará (CE), Rio Grande do Norte (RN), Paraíba (PB), Pernambuco (PE), Alagoas (AL), Sergipe (SE), Bahia (BA), Minas Gerais (MG), Espírito Santo (ES), Rio de Janeiro (RJ), São Paulo (SP), Paraná (PR), Santa Catarina (SC), Rio Grande do Sul (RS), Mato Grosso do Sul (MS), Mato Grosso (MT), Goiás (GO) e Distrito Federal (DF).
} 
No que pertine às atividades (concessão, pagamento e manutenção) de pensão por morte dos servidores de todos os poderes (administração direta e indireta do Executivo, Judiciário e Legislativo), nota-se que as mesmas são executadas diretamente por quase todas as unidades gestoras (apêndice B).

Esse equilíbrio na execução das atividades de pensão explicita a natureza histórica da organização das instituições previdenciárias do país, que sempre operacionalizaram as pensões, deixando as aposentadorias a cargo dos órgãos de recursos humanos dos servidores.

Quando se observa conjuntamente todos os poderes do Estado, verifica-se que 11 estados possuem unidades gestoras que executam diretamente todas as atividades de pensão dos funcionários públicos de todos os poderes. São eles: Tocantins, Rio Grande do Norte, Pernambuco, Alagoas, Sergipe, Bahia, Minas Gerais, Espírito Santo, Rio de Janeiro, São Paulo e Santa Catarina (quadro 2). Diferentemente do caso das aposentadorias, as pensões apresentam administração menos fragmentada. De todo modo, ainda não se faz pleno proveito das possíveis sinergias que se alcançariam na hipótese de unificação das atividades relativas aos benefícios de aposentadoria e pensão.

\section{Quadro 2}

Unidades gestoras dos RPPSs estaduais e do DF que realizam diretamente as atividades de concessão, pagamento e manutenção de pensão por morte dos servidores de todos os poderes e entidades - Brasil - 2011

\begin{tabular}{|l|c|c|c|c|c|c|c|c|c|c|c|c|c|c|}
\hline & RO & AC & AM & RR & PA & AP & TO & MA & PI & CE & RN & PB & PE & AL \\
\hline Executivo administração direta & $\mathrm{x}$ & $\mathrm{x}$ & $\mathrm{x}$ & - & - & $\mathrm{x}$ & $\mathrm{x}$ & - & $\mathrm{x}$ & & $\mathrm{x}$ & $\mathrm{x}$ & $\mathrm{x}$ & $\mathrm{x}$ \\
Executivo administração indireta & & $\mathrm{x}$ & $\mathrm{x}$ & - & - & & $\mathrm{x}$ & - & $\mathrm{x}$ & & $\mathrm{x}$ & $\mathrm{x}$ & $\mathrm{x}$ & $\mathrm{x}$ \\
\hline Judiciário & $\mathrm{x}$ & & & - & - & $\mathrm{x}$ & $\mathrm{x}$ & - & & & $\mathrm{x}$ & & $\mathrm{x}$ & $\mathrm{x}$ \\
\hline Legislativo & $\mathrm{x}$ & & & - & - & $\mathrm{x}$ & $\mathrm{x}$ & - & & & $\mathrm{x}$ & & $\mathrm{x}$ & $\mathrm{x}$ \\
\hline Todos os Poderes e Entidades & & & & & & & $\mathrm{x}$ & & & & $\mathrm{x}$ & & $\mathrm{x}$ & $\mathrm{x}$ \\
\hline
\end{tabular}

\begin{tabular}{|l|c|c|c|c|c|c|c|c|c|c|c|c|c|}
\hline & SE & BA & MG & ES & RJ & SP & PR & SC & RS & MS & MT & GO & DF \\
\hline Executivo administração direta & $\mathrm{x}$ & $\mathrm{x}$ & $\mathrm{x}$ & $\mathrm{x}$ & $\mathrm{x}$ & $\mathrm{x}$ & $\mathrm{x}$ & $\mathrm{x}$ & - & & - & - & - \\
Executivo administração indireta & $\mathrm{x}$ & $\mathrm{x}$ & $\mathrm{x}$ & $\mathrm{x}$ & $\mathrm{x}$ & $\mathrm{x}$ & $\mathrm{x}$ & $\mathrm{x}$ & - & & - & - & - \\
Judiciário & $\mathrm{x}$ & $\mathrm{x}$ & $\mathrm{x}$ & $\mathrm{x}$ & $\mathrm{x}$ & $\mathrm{x}$ & $\mathrm{x}$ & $\mathrm{x}$ & - & & - & - & - \\
\hline Legislativo & $\mathrm{x}$ & $\mathrm{x}$ & $\mathrm{x}$ & $\mathrm{x}$ & $\mathrm{x}$ & $\mathrm{x}$ & & $\mathrm{x}$ & - & & - & - & - \\
\hline Todos os Poderes e Entidades & $\mathrm{x}$ & $\mathrm{x}$ & $\mathrm{x}$ & $\mathrm{x}$ & $\mathrm{x}$ & $\mathrm{x}$ & & $\mathrm{x}$ & & & & & \\
\hline
\end{tabular}

Fonte: Elaborado pelos autores.

Nota: Questionários respondidos.

Observação: Entes que não responderam à pergunta: RR, PA, MA, RS, MT, GO e DF. Ceará não possui unidade gestora para executar as atividades dos RPPSs.

Quando se procura analisar quais entidades dos RPPSs dos estados e DF realizam diretamente todas as atividades (concessão, pagamento e manutenção) de aposentadoria e de 
pensão, percebe-se que existem apenas quatro estados que as executam: Tocantins, Sergipe, Minas Gerais e Espírito Santo (quadro 3). Isso mostra a dificuldade de se realizar gestão conjunta do RPPS dos três poderes. Esse fato pode ser particularmente prejudicial à racionalidade administrativa ao indicar a existência de multiplicidade desnecessária de atividades com prejuízo ao aproveitamento dos ganhos de escala.

\section{Quadro 3}

Unidades gestoras dos RPPSs estaduais e do DF que realizam diretamente as atividades de concessão, pagamento e manutenção de aposentadoria e pensão por morte dos servidores de todos os poderes e entidades - Brasil - 2011

\begin{tabular}{|l|c|c|c|c|c|c|c|c|c|c|c|c|c|c|}
\hline & RO & AC & AM & RR & PA & AP & TO & MA & PI & CE & RN & PB & PE & AL \\
\hline Aposentadoria & & & & - & - & & $x$ & - & & & & & & \\
Pensão por morte & & & & - & - & & $x$ & - & & & $x$ & & $x$ & $x$ \\
\hline Aposentadoria e pensão & & & & & & & $x$ & & & & & & & \\
\hline
\end{tabular}

\begin{tabular}{|l|c|c|c|c|c|c|c|c|c|c|c|c|c|}
\hline & SE & BA & MG & ES & RJ & SP & PR & SC & RS & MS & MT & GO & DF \\
\hline Aposentadoria & $\mathrm{x}$ & & $\mathrm{x}$ & $\mathrm{x}$ & & & & & - & & - & - & - \\
\hline Pensão por morte & $\mathrm{x}$ & $\mathrm{x}$ & $\mathrm{x}$ & $\mathrm{x}$ & $\mathrm{x}$ & $\mathrm{x}$ & & $\mathrm{x}$ & - & & - & - & - \\
\hline Aposentadoria e pensão & $\mathrm{x}$ & & $\mathrm{x}$ & $\mathrm{x}$ & & & & & & & & & \\
\hline
\end{tabular}

Fonte: Elaborado pelos autores. Nota: Questionários respondidos.

Observação: Entes que não responderam à pergunta: RR, PA, MA, RS, MT, GO e DF. Ceará não possui unidade gestora para executar as atividades dos RPPSs.

Em síntese (gráfico 1), conclui-se que a atividade "pagamento de aposentadoria" tem sido executada pelas entidades previdenciárias dos estados e DF em quase todos os poderes e que a execução das demais (concessão e manutenção) tende a se reduzir na medida em que o órgão se afasta do poder central, da administração direta do Poder Executivo do ente federativo. Quanto à pensão, nota-se grande uniformidade na realização de suas atividades pelas unidades gestoras no âmbito de todos os poderes.

No que se refere à publicação de lei prevendo a criação de unidade gestora do RPPS, constatou-se que, dos 22 entes que responderam ao questionário, há 20 que registraram a publicação da referida lei, com exceção dos estados de Roraima e Ceará. O representante desse último ente esclareceu que o motivo da não criação foi a falta de conhecimento técnico, enquanto o respondente de Roraima deixou o campo em branco.

Relativamente às principais razões que levaram à criação da unidade gestora dos RPPSs dos estados e DF foram: obediência às normas federais (17 respostas), manutenção do Certificado de Regularidade Previdenciária - CRP (14) e padronização e uniformização de procedimentos (12) (gráfico 2). 


$$
\text { Gráfico } 1
$$

Taxa de execução das atividades de concessão, pagamento e manutenção de aposentadoria e pensão por morte dos servidores de todos os Poderes e entidades realizadas pelas unidades gestoras dos RPPSs estaduais e do DF - Brasil - 2011

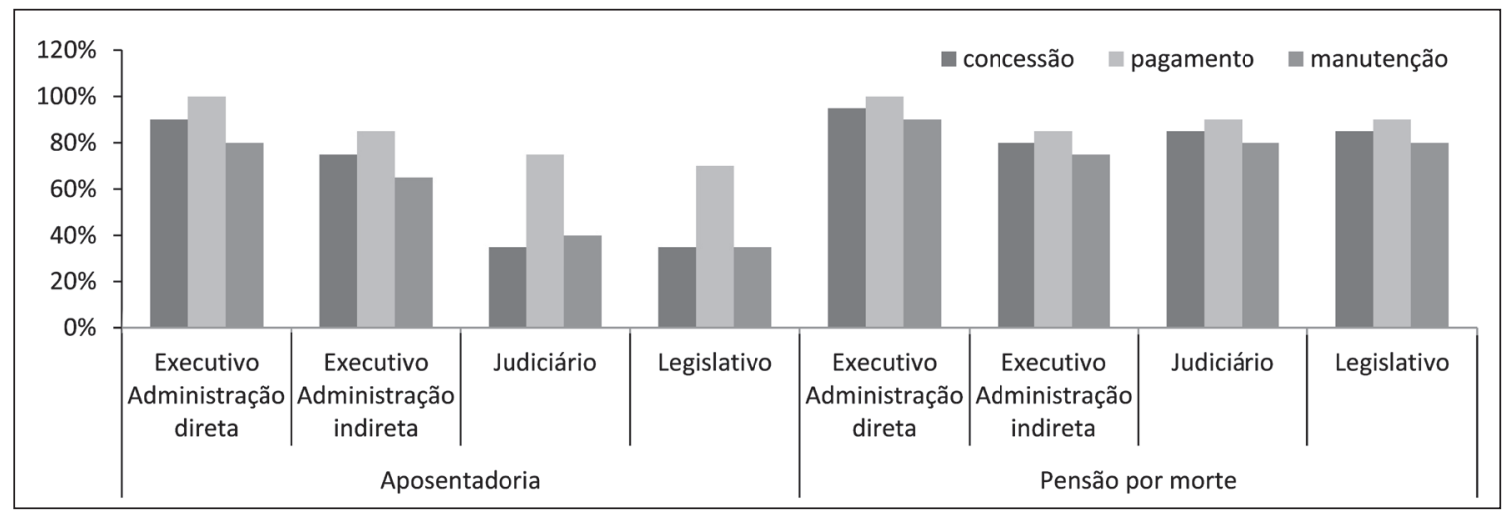

Fonte: Elaborado pelos autores.

Nota: Questionários respondidos.

Gráfico 2

Razões de criação das unidades gestoras dos RPPSs estaduais e do DF - Brasil - 2011

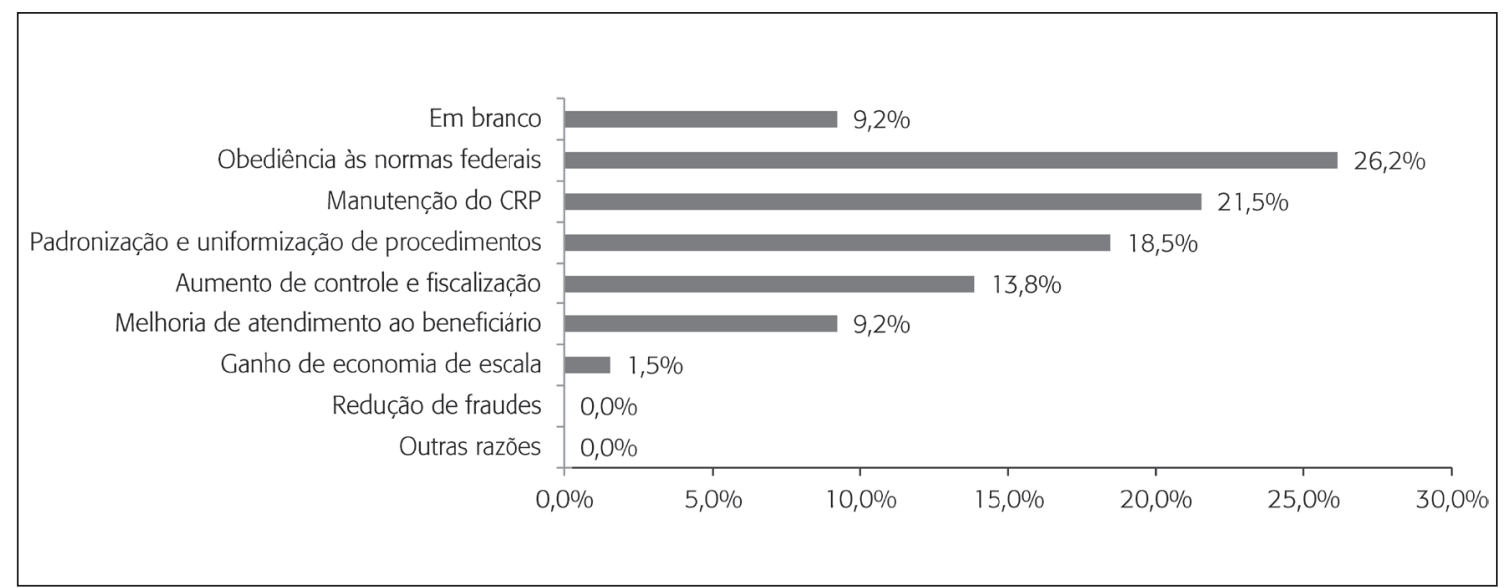

Fonte: Elaborado pelos autores.

Nota: Questionários respondidos.

Como a renovação do CRP pressupõe o atendimento às leis previdenciárias e tem como resultado lógico a liberação dos repasses voluntários de recursos financeiros pelas instituições federais aos estados e municípios, pode-se afirmar que a "obediência às normas" $(17+14=$ 31 respostas) foi a maior razão para esses RPPSs criarem a sua unidade gestora. 
Em outras palavras, os estados têm atitude passiva em relação à unificação da gestão previdenciária. Fazem-na simplesmente porque a lei assim determina. Não há uma busca pela eficiência administrativa e racionalização de procedimentos, ao menos neste item estudado da gestão previdenciária.

Ademais, como a melhoria de atendimento ao beneficiário foi uma das razões menos relatadas pelos estados e como a maior razão dos RPPSs para criarem as suas unidades gestoras foi a necessidade de obediência às normas, o resultado sugere menor atenção dos RPPSs dos estados e Distrito Federal em relação aos interesses de seus beneficiários.

Entre os 20 entes que publicaram lei de criação da unidade gestora, 13 - Rondônia, Acre, Amapá, Tocantins, Piauí, Rio Grande do Norte, Paraíba, Pernambuco, Sergipe, Bahia, Espírito Santo, São Paulo e Goiás — disseram que a entidade está implantada ${ }^{9}$ e sete — Mato Grosso do Sul, Sergipe, Paraná, Rio de Janeiro, Minas Gerais, Alagoas e Amazonas — afirmaram que está parcialmente implantada. $O$ resultado sugere dificuldade na implantação ${ }^{10}$ da unidade gestora.

Entre as três maiores dificuldades apontadas pelos entes para implantarem a unidade gestora, nove responderam que a maior foi a integração entre poderes e sistemas, quatro responderam "ausência de pessoal efetivo e estrutura administrativa" e três disseram que possuem dificuldades em cumprir a legislação. O resultado explicita que as maiores dificuldades são de ordens política (integração de poderes) e técnica (integração de sistemas) (gráfico 3).

Relativamente às unidades gestoras que já estão em funcionamento, procurou-se verificar quais delas executam as atividades que são de sua responsabilidade segundo as normas constitucionais e legais, quais sejam:

- administra e operacionaliza, de forma centralizada, o RPPS;

— arrecada e cobra, de forma centralizada, as contribuições previdenciárias;

- gere e aplica, de forma centralizada, os recursos financeiros do RPPS;

- gerencia e operacionaliza, de forma centralizada, as atividades de compensação financeira com o RGPS.

\footnotetext{
${ }^{9}$ Para os fins deste artigo, "implantação" significa disponibilização de estrutura organizacional e física para funcionamento da entidade gestora do RPPS.

${ }^{10} \mathrm{O}$ tempo de implantação das unidades gestoras dos RPPSs estaduais não foi analisado porque as perguntas $1 \mathrm{e}$ 1.2.1 do questionário solicitaram fosse informado apenas o ano de publicação da lei que previu a criação da entidade gestora e o ano de sua implantação, não solicitando fossem esclarecidos o mês de publicação da lei que a criou e o mês de sua implantação. Assim, poder-se-ia chegar a um absurdo de se ter estado da federação com diferença de zero ano, mas que gastou 11 meses entre a criação e a implantação da entidade gestora e outro, com diferença de um ano, que gastou apenas um mês para implantá-la.
} 
Gráfico 3

Dificuldades na implantação das unidades gestoras dos RPPSs estaduais e do DF - Brasil $-2011$

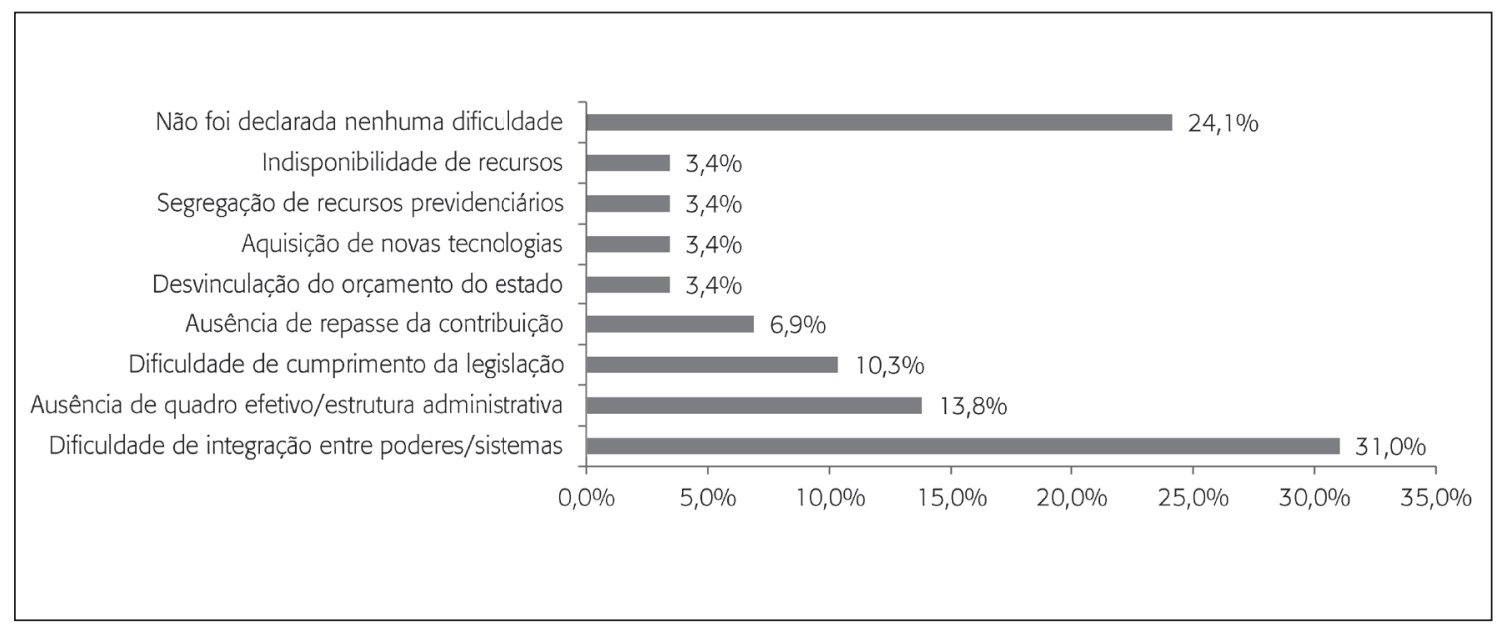

Fonte: Elaborado pelos autores.

Nota: Questionários respondidos.

De acordo com o quadro 4, apenas 11 entes possuem unidades gestoras que executam todas as atividades de responsabilidade dos RPPSs: Acre, Amazonas, Tocantins, Paraíba, Pernambuco, Alagoas, Bahia, Minas Gerais, Espírito Santo, São Paulo e Santa Catarina.

Entre os 11 estados acima listados, apenas o do Acre não possui unidade gestora com atribuição para gerir conjuntamente os RPPSs dos servidores e militares. Ou seja, além da gestão do RPPS dos servidores públicos (segundo exigência do $\S 20$ do art. 40 da CF/88), a unidade gestora de todos os outros dez estados detém competência adicional para gerir o RPPS dos seus militares.

Em relação à garantia da participação dos servidores estaduais e distritais em Conselho de Administração, detectou-se que todos os entes respondentes garantem a participação dos servidores no Conselho, com exceção do Ceará, que ainda não possui unidade gestora.

Quanto ao quesito paridade (número igual de representantes de servidores e do governo), nem todos os estados que garantem a participação dos servidores no Conselho Deliberativo respeitam a paridade. Dos 22 entes respondentes, 19 garantem a paridade. Como exemplo, Bahia, Sergipe e Paraná contam com a presença de servidores em seu Conselho Deliberativo, mas não na mesma proporção dos membros representantes do governo. 


\section{Quadro 4}

Atividades de responsabilidade dos RPPSs executadas pelas unidades gestoras dos RPPSs estaduais e do DF - Brasil - 2011

\begin{tabular}{|l|c|c|c|c|c|c|c|c|c|c|c|c|c|c|}
\hline & RO & AC & AM & RR & PA & AP & TO & MA & PI & CE & RN & PB & PE & AL \\
\hline $\begin{array}{l}\text { Administra e operacionaliza, de } \\
\text { forma centralizada, o RPPS. }\end{array}$ & & $\mathrm{x}$ & $\mathrm{x}$ & & & $\mathrm{x}$ & $\mathrm{x}$ & & $\mathrm{x}$ & & $\mathrm{x}$ & $\mathrm{x}$ & $\mathrm{x}$ & $\mathrm{x}$ \\
\hline $\begin{array}{l}\text { Arrecada e cobra, de forma } \\
\text { centralizada, as contribuições } \\
\text { destinadas ao custeio do RPPS. }\end{array}$ & $\mathrm{x}$ & $\mathrm{x}$ & $\mathrm{x}$ & & & $\mathrm{x}$ & $\mathrm{x}$ & & & & $\mathrm{x}$ & $\mathrm{x}$ & $\mathrm{x}$ & $\mathrm{x}$ \\
$\begin{array}{l}\text { Gere e aplica, de forma centralizada, } \\
\text { os recursos financeiros do RPPS. }\end{array}$ & & $\mathrm{x}$ & $\mathrm{x}$ & & & $\mathrm{x}$ & $\mathrm{x}$ & & & & & $\mathrm{x}$ & $\mathrm{x}$ & $\mathrm{x}$ \\
$\begin{array}{l}\text { Gerencia e operacionaliza, de forma } \\
\text { centralizada, as atividades de } \\
\text { compensação financeira com o RGPS. }\end{array}$ & & $\mathrm{x}$ & $\mathrm{x}$ & & & & $\mathrm{x}$ & & & & & $\mathrm{x}$ & $\mathrm{x}$ & $\mathrm{x}$ \\
\hline Executa todas as atividades do RPPS & & $\mathrm{x}$ & $\mathrm{x}$ & & & & $\mathrm{x}$ & & & & & $\mathrm{x}$ & $\mathrm{x}$ & $\mathrm{x}$ \\
\hline
\end{tabular}

\begin{tabular}{|c|c|c|c|c|c|c|c|c|c|c|c|c|}
\hline & $\mathrm{SE}$ & BA & MG & ES & $\mathrm{RJ}$ & SP & PR & SC & \begin{tabular}{|l|l|}
$\mathrm{RS}$ & $\mathrm{MS}$ \\
\end{tabular} & MT & $\mathrm{GO}$ & DF \\
\hline $\begin{array}{l}\text { Administra e operacionaliza, de } \\
\text { forma centralizada, o RPPS. }\end{array}$ & $x$ & $x$ & $x$ & $\mathrm{x}$ & & $x$ & $x$ & $x$ & & & $x$ & \\
\hline $\begin{array}{l}\text { Arrecada e cobra, de forma } \\
\text { centralizada, as contribuições } \\
\text { destinadas ao custeio do RPPS. }\end{array}$ & $x$ & $\mathrm{x}$ & $x$ & $\mathrm{x}$ & $\mathrm{x}$ & $x$ & & $\mathrm{x}$ & & & $\mathrm{x}$ & \\
\hline $\begin{array}{l}\text { Gere e aplica, de forma centralizada, } \\
\text { os recursos financeiros do RPPS. }\end{array}$ & $x$ & $x$ & $x$ & $x$ & $x$ & $x$ & $x$ & $x$ & & & & \\
\hline $\begin{array}{l}\text { Gerencia e operacionaliza, de forma } \\
\text { centralizada, as atividades de } \\
\text { compensação financeira com o RGPS. }\end{array}$ & & $x$ & $x$ & $x$ & $x$ & $x$ & $x$ & $x$ & $x$ & & $x$ & \\
\hline Executa todas as atividades do RPPS & & $x$ & $x$ & $\mathrm{x}$ & & $x$ & & $\mathrm{x}$ & & & & \\
\hline
\end{tabular}

Fonte: Elaborado pelos autores.

Nota: Questionários respondidos.

Observação: Ceará não possui unidade gestora para executar as atividades dos RPPSs.

No que se refere à garantia da participação dos servidores estaduais e distritais nos Conselhos Fiscais de seus RPPSs, apurou-se que quase todos os entes respondentes garantem a participação dos servidores, com exceção do Mato Grosso do Sul e Ceará (este, porque ainda não criou unidade gestora). Os estados de Sergipe e Paraná não garantem paridade dos representantes dos servidores no Conselho Fiscal, e o Conselho Fiscal do Rio de Janeiro é composto apenas por representantes dos servidores, o que possibilita uma atuação mais efetiva desses atores na fiscalização e no controle da gestão do RPPS. 
A participação social na gestão dos RPPS, especificamente no que se refere à representatividade dos servidores nos conselhos de administração e fiscal, aliada à existência de uma unidade gestora, proporciona maior eficiência, transparência e controle, de forma a impingir os gestores a buscarem a profissionalização da administração dos RPPSs.

O tempo de resposta aos requerimentos de aposentadoria e pensão de todos os RPPSs estaduais e do Distrito Federal tem se reduzido ao longo dos anos. Para todos os estados respondentes, as razões que levaram à sua redução foram ações de natureza gerencial (redesenho de fluxo de procedimentos, investimento em sistemas informatizados, capacitação de pessoal) e para apenas metade deles, a criação da unidade gestora (quadro 5). Os resultados sugerem haver maior relação entre "redução do tempo de resposta" e "ações de gestão" do que entre "redução do tempo de resposta" e "criação da unidade gestora".

\section{Quadro 5}

Razões da redução do tempo de resposta das unidades gestoras dos RPPSs estaduais e do DF aos pedidos de aposentadoria e pensão - Brasil - 2011

\begin{tabular}{|l|c|c|c|c|c|c|c|c|c|c|c|c|c|c|}
\hline & RO & AC & AM & RR & PA & AP & TO & MA & PI & CE & RN & PB & PE & AL \\
\hline Criação da Unidade Gestora do RPPS & & & $x$ & & - & $x$ & & - & & & $x$ & & $x$ & \\
\hline Ações de gestão & $\mathrm{x}$ & $\mathrm{x}$ & $\mathrm{x}$ & $\mathrm{x}$ & - & $\mathrm{x}$ & $\mathrm{x}$ & - & $\mathrm{x}$ & $\mathrm{x}$ & $\mathrm{x}$ & $\mathrm{x}$ & $\mathrm{x}$ & $\mathrm{x}$ \\
\hline Outras atribuições & & & & & - & & & - & & & & & & \\
\hline
\end{tabular}

\begin{tabular}{|l|c|c|c|c|c|c|c|c|c|c|c|c|c|}
\hline & SE & BA & MG & ES & RJ & SP & PR & SC & RS & MS & MT & GO & DF \\
\hline Criação da Unidade Gestora do RPPS & $\mathrm{x}$ & $\mathrm{x}$ & & & $\mathrm{x}$ & $\mathrm{x}$ & $\mathrm{x}$ & $\mathrm{x}$ & - & & - & $\mathrm{x}$ & - \\
\hline Ações de gestão & $\mathrm{x}$ & $\mathrm{x}$ & $\mathrm{x}$ & $\mathrm{x}$ & $\mathrm{x}$ & $\mathrm{x}$ & $\mathrm{x}$ & $\mathrm{x}$ & - & $\mathrm{x}$ & - & $\mathrm{x}$ & - \\
\hline Outras atribuições & & & & & & & & & - & & - & & - \\
\hline
\end{tabular}

Fonte: Elaborado pelos autores.

Nota: Questionários respondidos.

Observação: Entes que não responderam à pergunta: PA, MA, RS, MT e DF.

Dos 21 entes respondentes, ${ }^{11} 12$ operam fundo previdenciário em regime de capitalização (57\%), e 40\% deles criaram a capitalização no período de 2008-10; outros 40\%, de 2002-05; e os 20\% restantes, de 1998-99 (gráfico 4). O resultado sugere uma relação entre reforma do plano de custeio dos RPPSs (capitalização) e aumento da confiança dos entes federados em relação às orientações dimanadas do MPS, o que transparece o aumento da eficácia de seu poder regulador.

\footnotetext{
${ }^{11} \mathrm{O}$ estado do Acre foi desconsiderado por apresentar resposta inconsistente.
} 
Gráfico 4

RPPSs estaduais e do DF com fundo capitalizado e ano de capitalização - Brasil - 2011

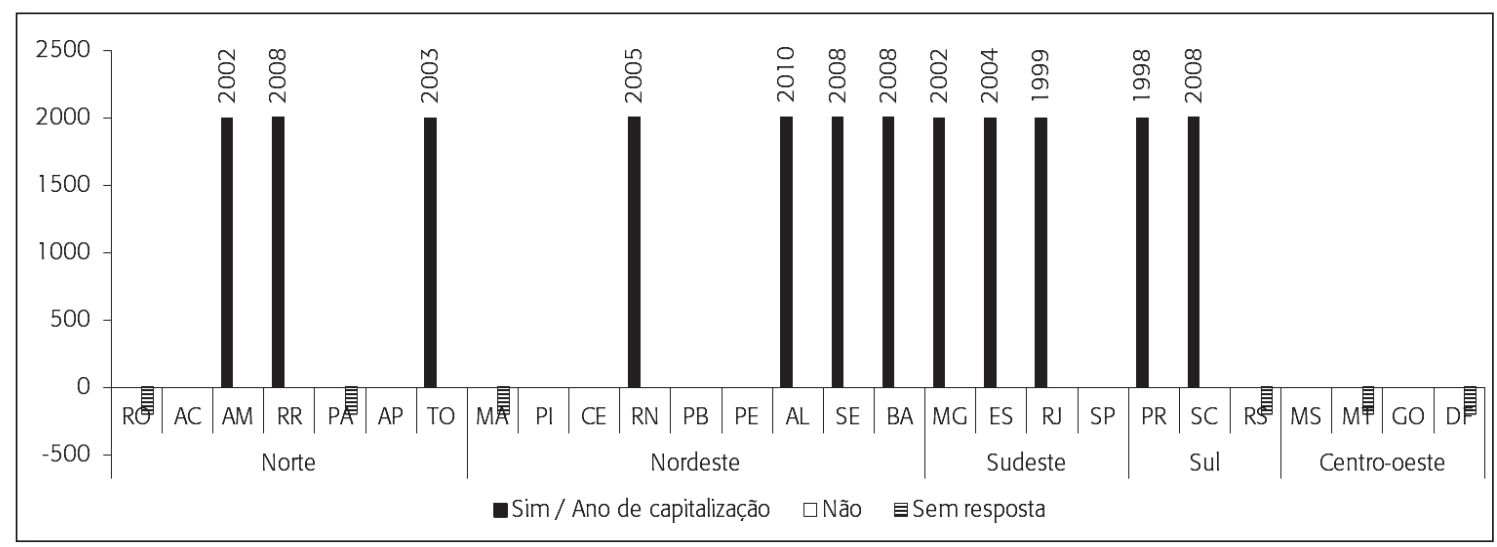

Fonte: Elaborado pelos autores.

Nota: Questionários respondidos.

Conforme abaixo demonstrado (quadro 6), os resultados sugerem forte relação entre unidade gestora implantada e participação dos servidores estaduais e distritais na gestão do RPPS via Conselho Deliberativo e vice-versa. Apenas o estado de Roraima não seguiu a tendência, já que garante a participação dos servidores no Conselho Deliberativo sem, contudo, possuir unidade gestora para o seu RPPS que supostamente legitimasse referida garantia.

\section{Quadro 6}

Relação entre unidade gestora implantada e participação de servidores estaduais e distritais na gestão do RPPS via Conselho Deliberativo - Brasil - 2011

\begin{tabular}{|l|c|c|c|c|c|c|c|c|c|c|c|c|c|c|}
\hline & RO & AC & AM & RR & PA & AP & TO & MA & PI & CE & RN & PB & PE & AL \\
\hline Há unidade gestora implantada & $\mathrm{x}$ & $\mathrm{x}$ & $\mathrm{x}$ & & - & $\mathrm{x}$ & $\mathrm{x}$ & - & $\mathrm{x}$ & & $\mathrm{x}$ & $\mathrm{x}$ & $\mathrm{x}$ & $\mathrm{x}$ \\
$\begin{array}{l}\text { Há garantia de participação de } \\
\text { servidor em conselho deliberativo }\end{array}$ & $\mathrm{x}$ & $\mathrm{x}$ & $\mathrm{x}$ & $\mathrm{x}$ & - & $\mathrm{x}$ & $\mathrm{x}$ & - & $\mathrm{x}$ & & $\mathrm{x}$ & $\mathrm{x}$ & $\mathrm{x}$ & $\mathrm{x}$ \\
\hline
\end{tabular}

\begin{tabular}{|l|c|c|c|c|c|c|c|c|c|c|c|c|c|}
\hline & SE & BA & MG & ES & RJ & SP & PR & SC & RS & MS & MT & GO & DF \\
\hline Há unidade gestora implantada & $\mathrm{x}$ & $\mathrm{x}$ & $\mathrm{x}$ & $\mathrm{x}$ & $\mathrm{x}$ & $\mathrm{x}$ & $\mathrm{x}$ & $\mathrm{x}$ & - & $\mathrm{x}$ & - & $\mathrm{x}$ & - \\
\hline $\begin{array}{l}\text { Há garantia de participação de } \\
\text { servidor em conselho deliberativo }\end{array}$ & $\mathrm{x}$ & $\mathrm{x}$ & $\mathrm{x}$ & $\mathrm{x}$ & $\mathrm{x}$ & $\mathrm{x}$ & $\mathrm{x}$ & $\mathrm{x}$ & - & $\mathrm{x}$ & - & $\mathrm{x}$ & - \\
\hline
\end{tabular}

Fonte: Elaborado pelos autores.

Nota: Questionários respondidos.

Observação: Entes que não responderam à pergunta: PA, MA, RS, MT e DF. Ceará não possui unidade gestora para executar as atividades dos RPPSs. 
Importante salientar que não foi possível verificar a existência de causalidade entre tais variáveis, já que não foi apurado se antes da criação da unidade gestora dos RPPSs estaduais e do DF a legislação já previa a participação dos servidores públicos nos conselhos deliberativos de seus RPPSs.

De acordo com o contido no quadro 7, os resultados também sugerem relação entre unidade gestora e redução dos tempos de resposta aos pedidos de aposentadoria e pensão. Apenas Roraima e Ceará não seguiram a tendência, já que têm reduzido o tempo de resposta sem, contudo, possuírem unidade gestora em seus RPPSs.

\section{Quadro 7}

Relação entre unidade gestora implantada e redução dos tempos de resposta aos pedidos de aposentadoria e pensão por morte - Brasil - 2011

\begin{tabular}{|l|c|c|c|c|c|c|c|c|c|c|c|c|c|c|}
\hline & RO & AC & AM & RR & PA & AP & TO & MA & PI & CE & RN & PB & PE & AL \\
\hline Unidade gestora implantada & $\mathrm{x}$ & $\mathrm{x}$ & $\mathrm{x}$ & & - & $\mathrm{x}$ & $\mathrm{x}$ & - & $\mathrm{x}$ & & $\mathrm{x}$ & $\mathrm{x}$ & $\mathrm{x}$ & $\mathrm{x}$ \\
$\begin{array}{l}\text { Tempo de resposta aos } \\
\text { pedidos de aposentadoria e } \\
\text { pensão tem se reduzido }\end{array}$ & $\mathrm{x}$ & $\mathrm{x}$ & $\mathrm{x}$ & $\mathrm{x}$ & - & $\mathrm{x}$ & $\mathrm{x}$ & - & $\mathrm{x}$ & $\mathrm{x}$ & $\mathrm{x}$ & $\mathrm{x}$ & $\mathrm{x}$ & $\mathrm{x}$ \\
\hline
\end{tabular}

\begin{tabular}{|l|c|c|c|c|c|c|c|c|c|c|c|c|c|}
\hline & SE & BA & MG & ES & RJ & SP & PR & SC & RS & MS & MT & GO & DF \\
\hline Unidade gestora implantada & $\mathrm{x}$ & $\mathrm{x}$ & $\mathrm{x}$ & $\mathrm{x}$ & $\mathrm{x}$ & $\mathrm{x}$ & $\mathrm{x}$ & $\mathrm{x}$ & - & $\mathrm{x}$ & - & $\mathrm{x}$ & - \\
\hline $\begin{array}{l}\text { Tempo de resposta aos } \\
\text { pedidos de aposentadoria e } \\
\text { pensão tem se reduzido }\end{array}$ & $\mathrm{x}$ & $\mathrm{x}$ & $\mathrm{x}$ & $\mathrm{x}$ & $\mathrm{x}$ & $\mathrm{x}$ & $\mathrm{x}$ & $\mathrm{x}$ & - & $\mathrm{x}$ & - & $\mathrm{x}$ & - \\
\hline
\end{tabular}

Fonte: Elaborado pelos autores.

Nota: Questionários respondidos.

Observação: Entes que não responderam à pergunta: PA, MA, RS, MT e DF. Ceará não possui unidade gestora para executar as atividades dos RPPSs.

Da mesma forma que a análise anterior, não restou constatada a causalidade entre as variáveis, já que não foi apurado se antes da criação da unidade gestora o tempo de resposta aos pedidos de aposentadoria e pensão por morte já vinha se reduzindo.

Por fim, no que se refere à possível relação existente entre unidade gestora e existência de fundo capitalizado, os resultados não confirmam tal conexão, posto que apenas metade dos entes respondentes (12 de 22) seguiu a tendência: Amazonas, Tocantins, Ceará, Rio Grande do Norte, Alagoas, Sergipe, Bahia, Minas Gerais, Espírito Santo, Rio de Janeiro, Paraná e Santa Catarina (quadro 8). 
Quadro 8

Relação entre unidade gestora implantada e existência de fundo capitalizado Brasil - 2011

\begin{tabular}{|l|c|c|c|c|c|c|c|c|c|c|c|c|c|c|}
\hline & RO & AC & AM & RR & PA & AP & TO & MA & PI & CE & RN & PB & PE & AL \\
\hline Há unidade gestora implantada & $\mathrm{x}$ & $\mathrm{x}$ & $\mathrm{x}$ & & - & $\mathrm{x}$ & $\mathrm{x}$ & - & $\mathrm{x}$ & & $\mathrm{x}$ & $\mathrm{x}$ & $\mathrm{x}$ & $\mathrm{x}$ \\
\hline Há fundo capitalizado & & & $\mathrm{x}$ & $\mathrm{x}$ & - & & $\mathrm{x}$ & - & & & $\mathrm{x}$ & & & $\mathrm{x}$ \\
\hline
\end{tabular}

\begin{tabular}{|l|c|c|c|c|c|c|c|c|c|c|c|c|c|}
\hline & SE & BA & MG & ES & RJ & SP & PR & SC & RS & MS & MT & GO & DF \\
\hline Há unidade gestora implantada & $\mathrm{x}$ & $\mathrm{x}$ & $\mathrm{x}$ & $\mathrm{x}$ & $\mathrm{x}$ & $\mathrm{x}$ & $\mathrm{x}$ & $\mathrm{x}$ & - & $\mathrm{x}$ & - & $\mathrm{x}$ & - \\
\hline Há fundo capitalizado & $\mathrm{x}$ & $\mathrm{x}$ & $\mathrm{x}$ & $\mathrm{x}$ & $\mathrm{x}$ & & $\mathrm{x}$ & $\mathrm{x}$ & - & & - & & - \\
\hline
\end{tabular}

Fonte: Elaborado pelos autores. Nota: Questionários respondidos.

Observação: Entes que não responderam à pergunta: PA, MA, RS, MT e DF. Ceará não possui unidade gestora para executar as atividades dos RPPSs.

\section{Considerações finais}

O objetivo geral do artigo buscou analisar as experiências dos estados e Distrito Federal na criação e no funcionamento das unidades gestoras de seus RPPSs. Para tanto, o artigo descreveu as origens e justificativa da exigência de criação de unidade gestora para os RPPSs; consignou o enquadramento normativo atual da matéria; sistematizou as propriedades conceituais de unidade gestora; verificou se os entes federados que participaram da pesquisa atendem às propriedades conceituais de unidade gestora e discutiu as razões e dificuldades de sua implantação. Verificou também se há relação entre unidade gestora implantada e: participação dos servidores na gestão do RPPS; evolução do tempo de resposta a pedidos de aposentadoria e pensão; e existência de fundo capitalizado. Ao final, apresentou os resultados deste ensaio empírico.

No que tange às origens e justificativa da exigência de criação de unidade gestora para os RPPSs, constatou-se que a fragmentação da operacionalização das atividades de concessão, pagamento e manutenção das aposentadorias de servidores públicos origina-se da relação "pro labore facto" havida entre estes e a administração pública. Referida situação necessita ser revista haja vista a evolução dos próprios paradigmas da Previdência Social dos Servidores Públicos, em que hoje não é mais vista como mera extensão da política de pessoal dos entes federados, mas benefício de caráter estritamente contributivo e que deve inclusive buscar preservar o equilíbrio financeiro e atuarial do sistema.

Nesse sentido é que se propõe criar entidades que sejam gestoras únicas dos RPPSs segundo a sistematização das propriedades conceituais de unidade gestora aqui elaborada: órgão/entidade integrante da estrutura do ente federado, com existência individualizada, com exceção dos militares, cuja competência é administrar o RPPS, mediante a realização 
consolidada das atividades de arrecadação e gestão de recursos, inclusive os derivados da compensação financeira com o RGPS, concessão, pagamento e manutenção de, no mínimo, aposentadorias e pensões concedidas a partir da EC no 41/2003, e que possua conselhos de administração e fiscal que garantam a representação paritária dos servidores.

Observou-se que, entre as atribuições constitucionais e legais de um RPPS, apenas podem ser considerados "unidades gestoras" os órgãos previdenciários de Tocantins, Minas Gerais e Espírito Santo, haja vista serem os únicos que atendem a todas as propriedades conceituais de unidade gestora sistematizadas neste artigo. ${ }^{12}$

A principal razão que levou os estados a criarem a unidade gestora de seus RPPSs foram obediência às normas e necessidade de manutenção do CRP (cujo fim último é o recebimento dos repasses voluntários da União) e não a preocupação com o beneficiário do regime, o que denota, em relação a esse aspecto, aparente falta de maturidade previdenciária.

As principais dificuldades descritas pelos RPPSs no instante da implantação da sua unidade gestora são de ordem política (integração dos poderes) e técnica (integração dos sistemas de pessoal), desenvolvidos numa época em que não havia preocupação com a questão previdenciária, motivo pelo qual as bases de dados cadastrais são limitadas no que se refere à gestão dessa política pública.

Verificou-se que, não obstante a criação da unidade gestora proporcionar ganhos de escala e aumento da eficiência da gestão dos RPPSs, sua inexistência não impede a promoção de melhorias na gestão dos RPPSs, que, por outros meios, suprem tal limitação organizacional, mediante redesenho de processos, melhorias tecnológicas e capacitação de pessoal.

O reconhecimento de relação havida entre unidade gestora implantada e: 1) participação dos servidores na gestão do regime de previdência; 2) evolução do tempo de resposta a requerimentos de aposentadoria e pensão; e 3) existência de fundo capitalizado denota a importância da unidade gestora no futuro dos RPPSs.

Todavia, indagação que não foi objeto de pesquisa e que merece análise é se haveria relação de causalidade entre unidade gestora implantada e as variáveis acima descritas. Para tanto, seria necessário analisar se, antes da criação da unidade gestora, havia previsão de participação de servidor nos conselhos deliberativos, se o tempo de resposta aos pedidos de aposentadoria e pensão já vinha se reduzindo e se o fundo capitalizado já tinha sido criado.

Constatou-se que a participação social na gestão dos RPPS, especificamente no que pertine à representatividade dos servidores nos conselhos deliberativo e fiscal, aliada à existência de uma unidade gestora, proporciona maior eficiência, transparência e controle, de forma a impingir os gestores a buscarem a profissionalização da administração dos RPPSs.

Pelo exposto, diante dos resultados alcançados e das indagações apresentadas, esperase ter contribuído para a melhoria da gestão dos RPPSs do país e a fim de que passem a ser

\footnotetext{
${ }^{12}$ A sistematização das propriedades conceituais de unidade gestora aqui tratada considera como válido o gerenciamento direto e indireto das atividades de aposentadoria e pensão. Todavia, a aplicação empírica desta sistematização foi feita com base na exigência do gerenciamento "direto", tal como formulada a pergunta "zero" do questionário.
} 
geridos de maneira cada vez mais eficiente e transparente e por meio da utilização de mecanismos democráticos de participação e diálogo sociais, que possibilitem um controle mais eficaz dessa política pública.

A discussão da problemática relativa às propriedades conceituais de unidade gestora permite aos gestores dos RPPSs realizarem análise introspectiva e tomarem essas informações como referência para o desenvolvimento de melhorias em seus regimes previdenciários.

Por fim, diante da necessidade, anteriormente exposta, de reformulação da gestão dos RPPSs no Brasil, oportuno destacar que tudo até agora exposto "implica em uma nova cultura previdenciária que deve ser paulatinamente absorvida pelos servidores e principalmente pelos gestores dos regimes previdenciários dos servidores públicos" (Silva, 2003:12).

\section{Referências}

ABRUCIO, Fernando L.; GAETANI, Francisco. Avanços e perspectivas da gestão pública nos estados: agenda, aprendizado e coalizão. 2006. Disponível em: < http://bresserpereira.org.br/Documents/ MARE/Terceiros-Papers/Texto\%20de\%20Abrucio\%20e\%20de\%20Gaetani.pdf > . Acesso em: 7 nov. 2011.

BRASIL. Instituto de Pesquisa Econômica Aplicada. Edição Especial, com resenhas por áreas temáticas e CD-ROM. Instituto de Pesquisa Econômica Aplicada, Brasília, texto para discussão ㄲo 1.000. 2004. Disponível em: <www.ipea.gov.br/pub/td/2003/td_1000.pdf>. Acesso em: 13 jan. 2010.

BRASIL. Ministério da Previdência e Assistência Social. Livro branco da Previdência Social. Brasília, dez. 2002. Disponível em: <www1.previdencia.gov.br/pg_secundarias/previdencia_social_14_ 06.asp>. Acesso em: 15 ago. 2006.

BRASIL. Ministério da Previdência Social. Anuário estatístico da Previdência Social 2009. Brasília. 2010a. Disponível em: <www.inss.gov.br/conteudoDinamico.php?id=974>. Acesso em: 4 ago. 2011.

BRASIL. Ministério da Previdência Social. Boletim estatístico da Previdência Social. Brasília, v. 15, n. 12, dez. 2010b. Disponível em: <www.mps.gov.br/conteudoDinamico.php?id=482>. Acesso em: 26 nov. 2011.

BRASIL. Ministério da Previdência Social. Boletim estatístico da Previdência Social. Brasília, v. 16, n. 1, jan. 2011. Disponível em: <www.inss.gov.br/conteudoDinamico.php?id=482>. Acesso em: 4 ago. 2011.

BRASIL. Secretaria do Tesouro Nacional. Boletim Despesa com Pessoal - Execução orçamentária. Brasília, 2009. Disponível em: <www.stn.gov.br/estatistica/est_boletim_despesa_pessoal.asp>. Acesso em: 10 out. 2011.

CAETANO, Marcelo A. Determinantes da sustentabilidade e do custo previdenciário: aspectos e comparações internacionais. Rio de Janeiro: Instituto de Pesquisa Econômica Aplicada, texto para 
discussão no 1.226, out. 2006. Disponível em: <www.ipea.gov.br/sites/000/2/publicacoes/tds/ td_1226.pdf $>$. Acesso em: 10 maio 2011.

CAETANO, Marcelo A. Instrumentos de controle da despesa com pessoal inativo e pensionistas de estados, municípios e do Distrito Federal. Rio de Janeiro: Instituto de Pesquisa Econômica Aplicada, texto para discussão no 1.502, jul. 2010. Disponível em: <www.ipea.gov.br/portal/images/stories/ PDFs/TDs/td_1502.pdf>. Acesso em: 10 maio 2011.

CALAZANS, Fernando F. A participação social na gestão dos regimes próprios de Previdência Social: o caso do Fundo de Previdência do Estado de Minas Gerais - FUNPEMG. Dissertação (mestrado) — Escola de Governo, Fundação João Pinheiro, Belo Horizonte, 2010.

CENTRO LATINOAMERICANO DE ADMINISTRACIÓN PARA EL DESARROLLO (CLAD), Consejo Científico del. La responsabilizatión ("accountability”) en la nueva gestión pública latinoamericana. In: CONSELHO CIENTÍFICO DEL CLAD. La responsabilización en la nueva gestión pública latinoamericana. Buenos Aires: Editorial Universitaria de Buenos Aires, 2000. p. 17-73.

DAGNINO, Evelina. Sociedade civil, participação e cidadania: de que estamos falando? In: MATO, Daniel (Coord.). Políticas de ciudadania y sociedade civil en tiempos de globalización. Caracas: Faces; Universidad Central de la Venezuela, 2004. p. 95-110. Disponível em: <http://168.96.200.17/ar/ libros/venezuela/faces/mato/Dagnino.pdf>. Acesso em: 19 ago. 2009.

GIAMBIAGI, Fábio. Diagnóstico da Previdência Social no Brasil: o que foi feito e o que falta reformar? Rio de Janeiro: Instituto de Pesquisa Econômica Aplicada, texto para discussão no 1.050, 17 out. 2004. Disponível em: <www.ipea.gov.br/pub/td/2004/td_1050.pdf>. Acesso em: 13 maio 2007.

PIRES, Roberto Rocha C. (Org.). Efetividade das instituições participativas no Brasil: estratégias de avaliação. Brasília: Ipea, 2011.

PUTNAM, Robert D. Comunidade e democracia: a experiência da Itália Moderna. Tradução de Luiz Alberto Monjardim. 4. ed. Rio de Janeiro: Editora FGV, 1996.

SCHWARZER, Helmut (Org.). Estudos e pesquisas da Secretaria de Políticas de Previdência Social. Brasília: Ministério da Previdência Social, 2009. (Previdência Social, Série Debates; v. 31)

SILVA, Delúbio Gomes P. da. Regime de previdência social dos servidores públicos no Brasil: perspectivas. São Paulo: LTr Editora Ltda, 2003.

SILVA, Frederico B. de; JACCOUD, Luciana; BEGHIN, Nathalie. Políticas sociais no Brasil: participação social, conselhos e parcerias. In: JACCOUD, Luciana (Org.). Questão social e políticas sociais no Brasil contemporâneo. Brasília: Ipea, 2005. p. 373-407.

SOUZA, Marcus V. de. Aposentadoria dos servidores não efetivos após a Emenda Constitucional nº 20/98: o caso da administração pública de Minas Gerais. Dissertação (mestrado) — Escola de Governo, Fundação João Pinheiro, Belo Horizonte, 2006.

TATAGIBA, Luciana. Os conselhos gestores e a democratização das políticas públicas no Brasil. In: DAGNINO, Evelina (Org.). Sociedade civil e espaços públicos no Brasil. Rio de Janeiro: Paz e Terra, 2002. p. 47-103. 


\section{Apêndice A}

Atividades de aposentadoria executadas pelas unidades gestoras dos RPPSs estaduais e do DF de acordo com os poderes e entidades

\section{Administração direta do Poder Executivo}

\begin{tabular}{|l|c|c|c|c|c|c|c|c|c|c|c|c|c|c|c|c|c|c|c|c|c|c|c|c|c|c|c|}
\hline & RO & AC & AM & RR & PA & AP & TO & MA & PI & CE & RN & PB & PE & AL & SE & BA & MG & ES & RJ & SP & PR & SC & RS & MS & MT & GO & DF \\
\hline Manutenção & $\mathrm{x}$ & $\mathrm{x}$ & $\mathrm{x}$ & & & $\mathrm{x}$ & $\mathrm{x}$ & & $\mathrm{x}$ & & & $\mathrm{x}$ & $\mathrm{x}$ & $\mathrm{x}$ & $\mathrm{x}$ & $\mathrm{x}$ & $\mathrm{x}$ & $\mathrm{x}$ & & $\mathrm{x}$ & $\mathrm{x}$ & $\mathrm{x}$ & & & & & \\
\hline Concessão & $\mathrm{x}$ & $\mathrm{x}$ & $\mathrm{x}$ & & & $\mathrm{x}$ & $\mathrm{x}$ & & $\mathrm{x}$ & & & $\mathrm{x}$ & $\mathrm{x}$ & $\mathrm{x}$ & $\mathrm{x}$ & $\mathrm{x}$ & $\mathrm{x}$ & $\mathrm{x}$ & $\mathrm{x}$ & $\mathrm{x}$ & $\mathrm{x}$ & $\mathrm{x}$ & & $\mathrm{x}$ & & & \\
\hline Pagamento & $\mathrm{x}$ & $\mathrm{x}$ & $\mathrm{x}$ & & & $\mathrm{x}$ & $\mathrm{x}$ & & $\mathrm{x}$ & $\mathrm{x}$ & $\mathrm{x}$ & $\mathrm{x}$ & $\mathrm{x}$ & $\mathrm{x}$ & $\mathrm{x}$ & $\mathrm{x}$ & $\mathrm{x}$ & $\mathrm{x}$ & $\mathrm{x}$ & $\mathrm{x}$ & $\mathrm{x}$ & $\mathrm{x}$ & & $\mathrm{x}$ & & & \\
\hline Todas as atividades & $\mathrm{x}$ & $\mathrm{x}$ & $\mathrm{x}$ & & & $\mathrm{x}$ & $\mathrm{x}$ & & $\mathrm{x}$ & & & $\mathrm{x}$ & $\mathrm{x}$ & $\mathrm{x}$ & $\mathrm{x}$ & $\mathrm{x}$ & $\mathrm{x}$ & $\mathrm{x}$ & $\mathrm{x}$ & $\mathrm{x}$ & $\mathrm{x}$ & $\mathrm{x}$ & & & & & \\
\hline
\end{tabular}

\section{Administração indireta do Poder Executivo}

\begin{tabular}{|l|c|c|c|c|c|c|c|c|c|c|c|c|c|c|c|c|c|c|c|c|c|c|c|c|c|c|c|}
\hline & RO & AC & AM & RR & PA & AP & TO & MA & PI & CE & RN & PB & PE & AL & SE & BA & MG & ES & RJ & SP & PR & SC & RS & MS & MT & GO & DF \\
\hline Manutenção & & $\mathrm{x}$ & $\mathrm{x}$ & & & & $\mathrm{x}$ & & $\mathrm{x}$ & & & $\mathrm{x}$ & $\mathrm{x}$ & $\mathrm{x}$ & $\mathrm{x}$ & $\mathrm{x}$ & $\mathrm{x}$ & $\mathrm{x}$ & & & $\mathrm{x}$ & $\mathrm{x}$ & & & & & \\
\hline Concessão & & $\mathrm{x}$ & $\mathrm{x}$ & & & & $\mathrm{x}$ & & $\mathrm{x}$ & & & $\mathrm{x}$ & $\mathrm{x}$ & $\mathrm{x}$ & $\mathrm{x}$ & $\mathrm{x}$ & $\mathrm{x}$ & $\mathrm{x}$ & $\mathrm{x}$ & & $\mathrm{x}$ & $\mathrm{x}$ & & $\mathrm{x}$ & & & \\
\hline Pagamento & & $\mathrm{x}$ & $\mathrm{x}$ & & & & $\mathrm{x}$ & & $\mathrm{x}$ & $\mathrm{x}$ & $\mathrm{x}$ & $\mathrm{x}$ & $\mathrm{x}$ & $\mathrm{x}$ & $\mathrm{x}$ & $\mathrm{x}$ & $\mathrm{x}$ & $\mathrm{x}$ & $\mathrm{x}$ & & $\mathrm{x}$ & $\mathrm{x}$ & & $\mathrm{x}$ & & & \\
\hline Todas as atividades & & $\mathrm{x}$ & $\mathrm{x}$ & & & & $\mathrm{x}$ & & $\mathrm{x}$ & & & $\mathrm{x}$ & $\mathrm{x}$ & $\mathrm{x}$ & $\mathrm{x}$ & $\mathrm{x}$ & $\mathrm{x}$ & $\mathrm{x}$ & & & $\mathrm{x}$ & $\mathrm{x}$ & & & & & \\
\hline
\end{tabular}

\section{Poder Judiciário}

\begin{tabular}{|l|c|c|c|c|c|c|c|c|c|c|c|c|c|c|c|c|c|c|c|c|c|c|c|c|c|c|c|}
\hline & RO & AC & AM & RR & PA & AP & TO & MA & PI & CE & RN & PB & PE & AL & SE & BA & MG & ES & RJ & SP & PR & SC & RS & MS & MT & GO & DF \\
\hline Manutenção & $\mathrm{x}$ & & & & & $\mathrm{x}$ & $\mathrm{x}$ & & & & & & & & $\mathrm{x}$ & & $\mathrm{x}$ & $\mathrm{x}$ & & & $\mathrm{x}$ & & & & & & \\
\hline Concessão & $\mathrm{x}$ & & & & & $\mathrm{x}$ & $\mathrm{x}$ & & $\mathrm{x}$ & $\mathrm{x}$ & $\mathrm{x}$ & $\mathrm{x}$ & $\mathrm{x}$ & & $\mathrm{x}$ & $\mathrm{x}$ & $\mathrm{x}$ & $\mathrm{x}$ & $\mathrm{x}$ & & $\mathrm{x}$ & & & $\mathrm{x}$ & & & \\
\hline Pagamento & $\mathrm{x}$ & & & & & $\mathrm{x}$ & $\mathrm{x}$ & & & & & $\mathrm{x}$ & & & $\mathrm{x}$ & & $\mathrm{x}$ & $\mathrm{x}$ & & & $\mathrm{x}$ & & & & & & \\
\hline Todas as atividades & $\mathrm{x}$ & & & & & $\mathrm{x}$ & $\mathrm{x}$ & & & & & & & & $\mathrm{x}$ & & $\mathrm{x}$ & $\mathrm{x}$ & & & $\mathrm{x}$ & & & & & & \\
\hline
\end{tabular}

\section{Poder Legislativo}

\begin{tabular}{|l|c|c|c|c|c|c|c|c|c|c|c|c|c|c|c|c|c|c|c|c|c|c|c|c|c|c|c|}
\hline & RO & AC & AM & RR & PA & AP & TO & MA & PI & CE & RN & PB & PE & AL & SE & BA & MG & ES & RJ & SP & PR & SC & RS & MS & MT & GO & DF \\
\hline Manutenção & $\mathrm{x}$ & $\mathrm{x}$ & & & & $\mathrm{x}$ & $\mathrm{x}$ & & & & & & & & $\mathrm{x}$ & & $\mathrm{x}$ & $\mathrm{x}$ & & & & & & & & & \\
\hline Concessão & $\mathrm{x}$ & & & & & $\mathrm{x}$ & $\mathrm{x}$ & & $\mathrm{x}$ & $\mathrm{x}$ & $\mathrm{x}$ & $\mathrm{x}$ & $\mathrm{x}$ & & $\mathrm{x}$ & $\mathrm{x}$ & $\mathrm{x}$ & $\mathrm{x}$ & $\mathrm{x}$ & & & & & $\mathrm{x}$ & & & \\
\hline Pagamento & $\mathrm{x}$ & & & & & $\mathrm{x}$ & $\mathrm{x}$ & & & & & $\mathrm{x}$ & & & $\mathrm{x}$ & & $\mathrm{x}$ & $\mathrm{x}$ & & & & & & & & & \\
\hline Todas as atividades & $\mathrm{x}$ & & & & & $\mathrm{x}$ & $\mathrm{x}$ & & & & & & & & $\mathrm{x}$ & & $\mathrm{x}$ & $\mathrm{x}$ & & & & & & & & & \\
\hline
\end{tabular}

Fonte: Elaborado pelos autores.

Nota: Questionários respondidos.

Observação: Entes que não responderam à pergunta: RR, PA, MA, RS, MT, GO e DF. 


\section{Apêndice B}

Atividades de pensão por morte executadas pelas unidades gestoras dos RPPSs estaduais e do DF de acordo com os poderes e entidades

\section{Administração direta do Poder Executivo}

\begin{tabular}{|l|c|c|c|c|c|c|c|c|c|c|c|c|c|c|c|c|c|c|c|c|c|c|c|c|c|c|c|}
\hline & RO & AC & AM & RR & PA & AP & TO & MA & PI & CE & RN & PB & PE & AL & SE & BA & MG & ES & R & SP & PR & SC & RS & MS & MT & GO & DF \\
\hline Manutenção & $\mathrm{x}$ & $\mathrm{x}$ & $\mathrm{x}$ & & & $\mathrm{x}$ & $\mathrm{x}$ & & $\mathrm{x}$ & & $\mathrm{x}$ & $\mathrm{x}$ & $\mathrm{x}$ & $\mathrm{x}$ & $\mathrm{x}$ & $\mathrm{x}$ & $\mathrm{x}$ & $\mathrm{x}$ & $\mathrm{x}$ & $\mathrm{x}$ & $\mathrm{x}$ & $\mathrm{x}$ & & $\mathrm{x}$ & & & \\
\hline Concessão & $\mathrm{x}$ & $\mathrm{x}$ & $\mathrm{x}$ & & & $\mathrm{x}$ & $\mathrm{x}$ & & $\mathrm{x}$ & $\mathrm{x}$ & $\mathrm{x}$ & $\mathrm{x}$ & $\mathrm{x}$ & $\mathrm{x}$ & $\mathrm{x}$ & $\mathrm{x}$ & $\mathrm{x}$ & $\mathrm{x}$ & $\mathrm{x}$ & $\mathrm{x}$ & $\mathrm{x}$ & $\mathrm{x}$ & & $\mathrm{x}$ & & & \\
\hline Pagamento & $\mathrm{x}$ & $\mathrm{x}$ & $\mathrm{x}$ & & & $\mathrm{x}$ & $\mathrm{x}$ & & $\mathrm{x}$ & & $\mathrm{x}$ & $\mathrm{x}$ & $\mathrm{x}$ & $\mathrm{x}$ & $\mathrm{x}$ & $\mathrm{x}$ & $\mathrm{x}$ & $\mathrm{x}$ & $\mathrm{x}$ & $\mathrm{x}$ & $\mathrm{x}$ & $\mathrm{x}$ & & & & & \\
\hline Todas as atividades & $\mathrm{x}$ & $\mathrm{x}$ & $\mathrm{x}$ & & & $\mathrm{x}$ & $\mathrm{x}$ & & $\mathrm{x}$ & & $\mathrm{x}$ & $\mathrm{x}$ & $\mathrm{x}$ & $\mathrm{x}$ & $\mathrm{x}$ & $\mathrm{x}$ & $\mathrm{x}$ & $\mathrm{x}$ & $\mathrm{x}$ & $\mathrm{x}$ & $\mathrm{x}$ & $\mathrm{x}$ & & & & & \\
\hline
\end{tabular}

\section{Administração indireta do Poder Executivo}

\begin{tabular}{|c|c|c|c|c|c|c|c|c|c|c|c|c|c|c|c|c|c|c|c|c|}
\hline & $\begin{array}{lll}\mathrm{RO} & \mathrm{AC} \\
\end{array}$ & AM & $\begin{array}{lll}\mathrm{RR} & \mathrm{PA} & A \\
\end{array}$ & \begin{tabular}{l|l|l} 
AP & TO & $M$ \\
\end{tabular} & \begin{tabular}{l|l|}
$M A$ & $P I$ \\
\end{tabular} & DE & $\mathrm{RN}$ & PB & $\mathrm{PE}$ & $\mathrm{AL}$ & & $B A$ & $M G$ & \begin{tabular}{l|l}
$E S$ & $R$ \\
\end{tabular} & & PR & & \begin{tabular}{l|l|l|} 
RS & MS \\
\end{tabular} & & \begin{tabular}{l|l|l|}
0 & $D F$ \\
\end{tabular} \\
\hline Manutenção & \begin{tabular}{|l|l|} 
& $x$ \\
\end{tabular} & $x$ & & $|x|$ & $x$ & $x$ & $x$ & $x$ & $x$ & $x$ & $x$ & $x$ & $\mathrm{x}$ & \begin{tabular}{l|l}
$x$ & $x$ \\
\end{tabular} & $x \mid x$ & $x$ & $x$ & 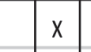 & & \\
\hline Concessão & $x$ & $x$ & & $x$ & $x$ & $x$ & $x$ & $x$ & $x$ & $x$ & $x$ & $x$ & $x$ & \begin{tabular}{l|l}
$x$ & $x$ \\
\end{tabular} & $x \mid x$ & $x$ & $x$ & $x$ & & \\
\hline Pagamento & $x$ & $x$ & & $x$ & $x$ & $x$ & $x$ & $x$ & $x$ & $x$ & $x$ & $x$ & $x$ & \begin{tabular}{l|l}
$x$ & $x$ \\
\end{tabular} & $x \quad x$ & $x$ & $x$ & & & \\
\hline Todas as atividades & $x$ & $x$ & & $x$ & $x$ & $x$ & $x$ & $x$ & $x$ & $x$ & $x$ & $x$ & $x$ & \begin{tabular}{l|l}
$x$ & $x$ \\
\end{tabular} & $x$ & $x$ & $x$ & & & \\
\hline
\end{tabular}

\section{Poder Judiciário}

\begin{tabular}{|l|c|c|c|c|c|c|c|c|c|c|c|c|c|c|c|c|c|c|c|c|c|c|c|c|c|c|c|}
\hline & RO & AC & AM & RR & PA & AP & TO & MA & PI & CE & RN & PB & PE & AL & SE & BA & MG & ES & R & SP & PR & SC & RS & MS & MT & GO & DF \\
\hline Manutenção & $\mathrm{x}$ & & & & & $\mathrm{x}$ & $\mathrm{x}$ & & & & $\mathrm{x}$ & & $\mathrm{x}$ & $\mathrm{x}$ & $\mathrm{x}$ & $\mathrm{x}$ & $\mathrm{x}$ & $\mathrm{x}$ & $\mathrm{x}$ & $\mathrm{x}$ & $\mathrm{x}$ & $\mathrm{x}$ & & & & & \\
\hline Concessão & $\mathrm{x}$ & & & & & $\mathrm{x}$ & $\mathrm{x}$ & & $\mathrm{x}$ & $\mathrm{x}$ & $\mathrm{x}$ & $\mathrm{x}$ & $\mathrm{x}$ & $\mathrm{x}$ & $\mathrm{x}$ & $\mathrm{x}$ & $\mathrm{x}$ & $\mathrm{x}$ & $\mathrm{x}$ & $\mathrm{x}$ & $\mathrm{x}$ & $\mathrm{x}$ & & $\mathrm{x}$ & & & \\
\hline Pagamento & $\mathrm{x}$ & & & & & $\mathrm{x}$ & $\mathrm{x}$ & & & & $\mathrm{x}$ & $\mathrm{x}$ & $\mathrm{x}$ & $\mathrm{x}$ & $\mathrm{x}$ & $\mathrm{x}$ & $\mathrm{x}$ & $\mathrm{x}$ & $\mathrm{x}$ & $\mathrm{x}$ & $\mathrm{x}$ & $\mathrm{x}$ & & & & & \\
\hline Todas as atividades & $\mathrm{x}$ & & & & & $\mathrm{x}$ & $\mathrm{x}$ & & & & $\mathrm{x}$ & & $\mathrm{x}$ & $\mathrm{x}$ & $\mathrm{x}$ & $\mathrm{x}$ & $\mathrm{x}$ & $\mathrm{x}$ & $\mathrm{x}$ & $\mathrm{x}$ & $\mathrm{x}$ & $\mathrm{x}$ & & & & & \\
\hline
\end{tabular}

\section{Poder Legislativo}

\begin{tabular}{|l|c|c|c|c|c|c|c|c|c|c|c|c|c|c|c|c|c|c|c|c|c|c|c|c|c|c|c|}
\hline & RO & AC & AM & RR & PA & AP & TO & MA & PI & CE & RN & PB & PE & AL & SE & BA & MG & ES & R & SP & PR & SC & RS & MS & MT & GO & DF \\
\hline Manutenção & $\mathrm{x}$ & $\mathrm{x}$ & & & & $\mathrm{x}$ & $\mathrm{x}$ & & & & $\mathrm{x}$ & & $\mathrm{x}$ & $\mathrm{x}$ & $\mathrm{x}$ & $\mathrm{x}$ & $\mathrm{x}$ & $\mathrm{x}$ & $\mathrm{x}$ & $\mathrm{x}$ & & $\mathrm{x}$ & & & & & \\
\hline Concessão & $\mathrm{x}$ & & & & & $\mathrm{x}$ & $\mathrm{x}$ & & $\mathrm{x}$ & $\mathrm{x}$ & $\mathrm{x}$ & $\mathrm{x}$ & $\mathrm{x}$ & $\mathrm{x}$ & $\mathrm{x}$ & $\mathrm{x}$ & $\mathrm{x}$ & $\mathrm{x}$ & $\mathrm{x}$ & $\mathrm{x}$ & $\mathrm{x}$ & $\mathrm{x}$ & $\mathrm{x}$ & & & \\
\hline Pagamento & $\mathrm{x}$ & & & & & $\mathrm{x}$ & $\mathrm{x}$ & & & & $\mathrm{x}$ & $\mathrm{x}$ & $\mathrm{x}$ & $\mathrm{x}$ & $\mathrm{x}$ & $\mathrm{x}$ & $\mathrm{x}$ & $\mathrm{x}$ & $\mathrm{x}$ & $\mathrm{x}$ & $\mathrm{x}$ & & & & & \\
\hline Todas as atividades & $\mathrm{x}$ & & & & & $\mathrm{x}$ & $\mathrm{x}$ & & & & $\mathrm{x}$ & & $\mathrm{x}$ & $\mathrm{x}$ & $\mathrm{x}$ & $\mathrm{x}$ & $\mathrm{x}$ & $\mathrm{x}$ & $\mathrm{x}$ & $\mathrm{x}$ & & $\mathrm{x}$ & & & & & \\
\hline
\end{tabular}

Fonte: Elaborado pelos autores.

Nota: Questionários respondidos.

Observação: Entes que não responderam à pergunta: RR, PA, MA, RS, MT, GO e DF. 
Fernando Ferreira Calazans é assessor jurídico da Secretaria de Gestão Previdenciária do Município de Belo Horizonte. E-mail: fernando_ffc@yahoo.com.br.

Marcus Vinicius de Souza é diretor de previdência do Instituto de Previdência dos Servidores do Estado de Minas Gerais. E-mail: mvsvhm@yahoo.com.br.

Karina Damião Hirano é diretora administrativa da Fundação de Previdência Complementar do Estado de São Paulo (SP-Prevcom). E-mail: khirano@sp.gov.br.

Renata Malpica Caldeira é assessora em Previdência Complementar da Fundação de Previdência Complementar do Estado de São Paulo (SP-Prevcom). E-mail: rcaldeira@sp.gov.br.

Maria de Lourdes Pinheiro da Silva é diretora especial de finanças da Secretaria da Fazenda do Estado de Alagoas. E-mail: pinheirolourdes@hotmail.com.

Pedro Emanuel Teixeira Rocha é coordenador de arrecadação da Superintendência de Previdência do Estado da Bahia. E-mail: pedrogestor@yahoo.com.br.

Marcelo Abi-Ramia Caetano é técnico de planejamento e pesquisa do Instituto de Pesquisa Econômica Aplicada. E-mail: mcaetano70@yahoo.com.br. 